\title{
The Silent Cooperator: An Epigenetic Model for Emergence of Altruistic Traits in Biological Systems
}

\author{
I. Hashem, D. Telen, P. Nimmegeers, and J. Van Impe \\ Chemical Engineering Department, KU Leuven, BioTeC and OPTEC, Gebroeders De Smetstraat 1, 9000 Ghent, Belgium \\ Correspondence should be addressed to J. Van Impe; jan.vanimpe@kuleuven.be
}

Received 8 December 2017; Revised 26 April 2018; Accepted 27 May 2018; Published 18 September 2018

Academic Editor: Hiroki Sayama

Copyright (c) 2018 I. Hashem et al. This is an open access article distributed under the Creative Commons Attribution License, which permits unrestricted use, distribution, and reproduction in any medium, provided the original work is properly cited.

\begin{abstract}
Spatial evolutionary game theory explains how cooperative traits can survive the intense competition in biological systems. If the spatial distribution allows cooperators to interact with each other frequently, the benefits of cooperation will outweigh the losses due to exploitation by selfish organisms. However, for a cooperative behavior to get established in a system, it needs to be found initially in a sufficiently large cluster to allow a high frequency of intracooperator interactions. Since mutations are rare events, this poses the question of how cooperation can arise in a biological system in the first place. We present a simple model which captures two concepts from genetics that can explain how evolution overcomes the emergence problem. The first concept is, often in nature, a gene may not express its phenotype except under specific environmental conditions, rendering it to be a "silent" gene. The second key idea is that a neutral gene, one that does not harm or improve an organism's survival chances, can still spread through a population if it is physically near to another gene that is positively selected. Through these two ideas, our model offers a possible solution to the fundamental problem of emergence of cooperation in biological systems.
\end{abstract}

\section{Introduction}

Cooperation is an unexpected product of evolution. In a struggle and race for existence between living organisms, it is intriguing that cooperative phenomena are widely spread in nature: bacteria share enzymes among each other to boast their overall growth; altruistic insects defend their colonies and, in the process, waste their shot at reproduction; and humans engage in a wide spectrum of altruistic activities, from paying taxes to donating to complete strangers. Cooperation is indeed widespread across all levels of biological societies $[1,2]$. However, despite this fact, classic evolutionary game theory could not explain how cooperators in nature can survive the risk of being exploited by "cheaters," organisms that aim to maximize their self-interest. This problem can be illustrated mathematically using the prisoner's dilemma as a game of evolution. The prisoner's dilemma is a standard example in game theory that can model a wide range of cooperative phenomena in a variety of biological systems, including viruses [3], cancer cells [4], bacterial life [5], and mammals [6].
The payoffs for a prisoner's dilemma (PD) game are summarized in Table 1. A cooperator provides a gain $g$ and endures a cooperation cost $c$. Defectors receive nothing when encountering each other. In contrast, if both agents are cooperative, each of them gets $g-c$. A cooperator interacting with a defector gets a payoff of $-c$ as it gets exploited. On the other hand, the defector reaps the benefit of exploitation $g$ without bearing any cost. Hence, it is seen that while cooperation is better for the group, defection is always better for the individual. A possible solution to this problem has been offered in the framework of spatial evolutionary game theory [2]. Including the effects of spatial arrangements can make the higher frequency of interactions among cooperators compensate the losses due to encounters with cheaters. The results of including spatial dimensions in the study of evolution of cooperation have been demonstrated by numerous studies [2, 7-9]. In [2], cells playing a PD game with each other are distributed on a square lattice. In a biological model, cells do not choose their strategies. Instead, they are genetically programmed to be either defectors or cooperators as they model living organisms. At each round, every cell 
TABLE 1: Payoffs for agent $a$ against agent $b$ in a prisoner's dilemma game; $g>0$ and $c>0$.

\begin{tabular}{ccc}
\hline$b$ & $\mathrm{C}$ & $\mathrm{D}$ \\
$a$ & $g-c$ & $-c$ \\
$\mathrm{C}$ & $g$ & 0 \\
$\mathrm{D}$ & & \\
\hline
\end{tabular}

plays a PD game with each of its neighbors. After that, a cell's fitness, the sum of the games' payoffs, is compared with its neighbors. If a neighbor has higher fitness than the focal cell, the focal cell dies and its location gets repopulated by a cell with the same strategy of the most successful neighbor. Similar studies have been performed using different update rules $[7,9]$ and on other social games, a public good game, for instance [10], showing that cooperative traits can survive on a lattice under certain parameter ranges.

A feature such models share is that for cooperators to do a successful invasion in a world of defectors, an initial cluster of cooperators is needed $[2,7,8,11]$. Spatial effects can only come to play if a cooperator interacts frequently with other cooperators. Hence, there is always a need of a critical population size of altruists so that they can survive and, in some situations, invade a lattice of selfish cells. The problem is even more severe in a public good game in which cooperators do not reap the benefits of cooperation except when their population reaches a critical threshold [12]. This raises the problem of how a simple cooperative trait can first emerge in a competitive biological system. We define a simple trait as one that does not get adjusted depending on the specific interaction it is involved in. Thus, it does not rely on complex behaviors such as punishment, memory, or communication. One possible answer to how simple cooperative traits appear is that with high enough population, and very long time, a highly unlikely coincidence could happen resulting in the formation of a cluster of cooperators exceeding the critical size. This can occur due to a number of mutations happening very close to each other or by introducing uncertainty in the game rules such that there is a tiny probability that a cooperator with low payoffs will invade a defector with higher payoffs. A common view currently in explaining the emergence of a simple cooperative strategy is that in a biological system, given enough time, even a highly unlikely event can happen [13].

In this paper, we aim to provide an alternative solution to the problem of emergence of cooperation. By means of known genetic phenomena, we show how a cooperative mutation can overcome the hurdle of the initial cluster size to establish itself in a biological system. The paper is structured as follows: Section 2 describes the concept and formulation of the spatial cooperation model examined in this work. The results and a discussion of the key parameters of the model are provided in Section 3. Finally, Section 4 summarizes the paper's conclusions.

\section{Materials and Methods}

The model presented in this section is inspired by how social bacteria overcome the problem of establishing cooperation when growing in a biofilm mode, a highly competitive biological system. Hence, before introducing our model, we first take a closer look into the social life of one of the most successful communities in earth: biofilms.

2.1. Cooperation in Biofilms. A biofilm is a community of bacterial cells living together on a surface enclosed by a self-produced polymeric matrix. The biofilm lifecycle starts with the colonization of a surface by motile microorganisms which get attached to the surface. Subsequently, they grow by cell division till a mature biofilm is formed. Finally, the dispersal of cells from its top leads to the colonization of new surfaces [14]. During the growth phase of a biofilm, bacteria often engage in cooperative behaviors, such as the production of extracellular enzymes to break down the nutrients for the benefit of the whole group and growing at a slower mode with a higher yield to increase the nutrient availability to the population as a whole. The distinctive feature of biofilms which allows cooperative traits to persist is the extracellular matrix, since it causes diffusion limitations in the biofilm and hence intensifies the spatial effects of segregation. In a study by [15], it is shown that cooperative cells can survive in a lowly mixed biofilm owing to the diffusion constraints of the polymeric matrix which reduce the effects of exploitation of cooperators by surrounding selfish cells. This result parallels the conclusion of $[2,11]$ at the more abstract setting of a spatial PD game.

On the other hand, in a highly mixed biofilm, such constitutive cooperative cells cannot survive as they will be outgrown by selfish cells. Hence, the need for more complex cooperative strategies arises. One technique by which cooperation can emerge in a highly mixed biofilm is quorum sensing. Quorum sensing is the process of producing chemical signals by bacterial cells to accumulate in the biofilm. When the concentration of the signals sensed by the cell reaches a certain threshold, quorum, it induces a change in the behavior/phenotype of the cell. In a study by [16], when colonizing a new surface, it is shown that cooperative cells using quorum sensing can dominate highly mixed biofilms by delaying the expression of their cooperative gene. In the beginning, the cooperative gene is unexpressed. However, as the biofilm grows, the density of cooperative quorumsensing cells increases as well as the concentration of their chemical signals. The quorum signal concentration eventually reaches the threshold required for activating the cooperative gene. By that time, quorum-sensing cells are spatially segregated from selfish cells. Hence, they are less likely to be exploited, and they dominate the biofilm. Quorum sensing effectively acts as a timer to delay the expression of an altruistic trait till the cells having the "silent" cooperative genes become spatially separated from selfish cells [16]. Thus, it reduces the risks of cooperative cells being exploited and increases their benefits from cooperation. This represents a highly sophisticated behavior where bacterial cells deliberately delay the expression of the cooperative gene till segregation occurs. By the means of quorum sensing, the silent gene gets activated by a change in environment that the bacteria themselves induce. This way, cooperative cells overcome the early highly mixed phase of the colonization process. 


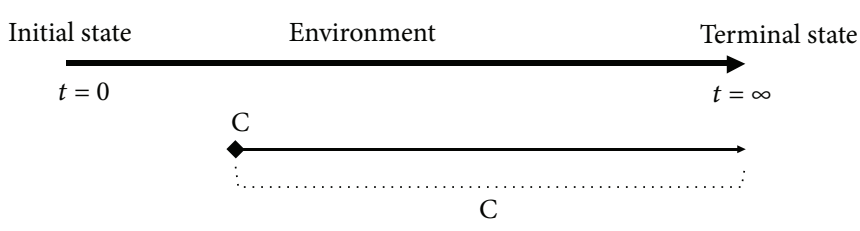

(a) Appearance of a cooperative gene $(C)$ in the population that is always expressed, at any environmental condition

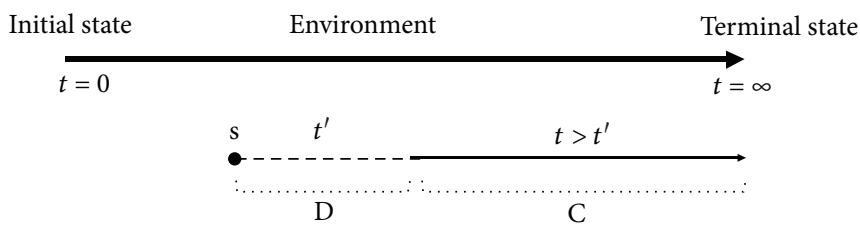

(b) Appearance of a gene (S) that requires a future state of the environment to be expressed. Till then, the gene carriers act as defective (D)

FiguRE 1: Silent genes: gene expression is often dependent on environmental factors. At their absence, the gene will stay unexpressed, although it can still be inherited and, in certain cases, spread in a population. The initial and terminal states here could represent low/high temperature, $\mathrm{pH}$, or any combination of environmental triggers required for the activation of the gene in hand.

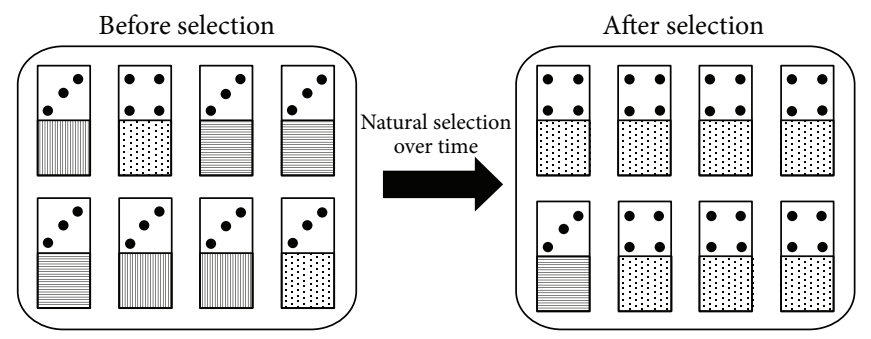

FIGURE 2: Genetic hitchhiking: the frequency of a gene could increase in the population due to lying at the same chromosome of another advantageous gene. In these "domino organisms," the top gene, the number of dots, represents a trait that is advantageous to its carrier, such as resistance to toxins or diseases. Hence, as the domino organisms with the highest dot number get positively selected, their bottom genes, which have no influence on their fitness, also spread in the population.

It should be noted that cooperative biofilm species have developed such sophisticated behavior as a result of immense selection pressure and the crucial need to establish cooperation in newborn communities repeatedly as they colonize new surfaces [16]. Using quorum sensing, they efficiently fine-tune the timing of the expression of their cooperative genes. Nevertheless, the concept of emergence of cooperation by a silent gene that gets activated at a future point of time due to possible changes in environmental conditions can still be a route for emergence of cooperation in general biological systems, as we will explain in the next section.

2.2. Model Concept. Once it is established in a population, a cooperative gene could be evolutionary stable if the population structure allows high frequency of intracooperator interactions $[2,11]$. However, a mutation resulting in a cooperative trait, such as the production of public good or sharing vital resources, faces steep odds in order to spread in a biological system in the first place. To explain a possible route for the emergence of cooperation, our model relies on two genetic phenomena. Firstly, it is common in nature that gene expression could rely on environmental factors $[17,18]$. A gene could give rise to a certain phenotype only beyond certain temperature [19], concentration of a chemical such as oxygen [20], or the $\mathrm{pH}$ level of the environment [21]. This alteration of gene expression due to nongenetic influences is referred to as epigenetic activation [22]. In the absence of the appropriate level of the environmental factor to trigger it, a gene could stay unexpressed (silent) with neither positive nor negative impact on the organism's fitness [18]. Hence, as illustrated in Figure 1, for a cooperative trait to first appear in a population via a mutation, it can be either through a gene that has been instantly expressed, as a consequence of being at the required environmental conditions/ needing no environmental trigger to be active, or as a silent gene that will be activated at under the appropriate environmental conditions at a point in the future. In the latter case, the silent cooperative trait has a time interval at which it exerts no influence on its carriers' fitness. During this interval, if it happened to spread to sufficient extent in the population, the cooperative trait could be evolutionary stable in the population by the time it gets expressed.

This brings us to the question of how a gene that does not alter the fitness of its carrier, such as silent genes, could possibly spread in a population. A possible mechanism is genetic hitchhiking. First proposed by [23], it is the increase in the frequency of a gene in the population not because it is itself under positive selection but due to being physically close, on the same DNA chain, of another gene that is beneficial to the organism and, hence, under positive selection [24], as illustrated in Figure 2.

As a consequence of combining the two ideas, a possible route for the emergence of an altruistic trait could be suggested, as illustrated in Figure 3. If a mutation produced a cooperative trait in the absence of the required abundance of the environmental factors necessary for its expression, the silent gene will not get exploited. Additionally, if it happened to hitchhike a selective sweep of another beneficial gene till it exceeds a critical spatial distribution, it could get established in the population once it gets triggered as the environment evolves to a more favorable state for its expression. 


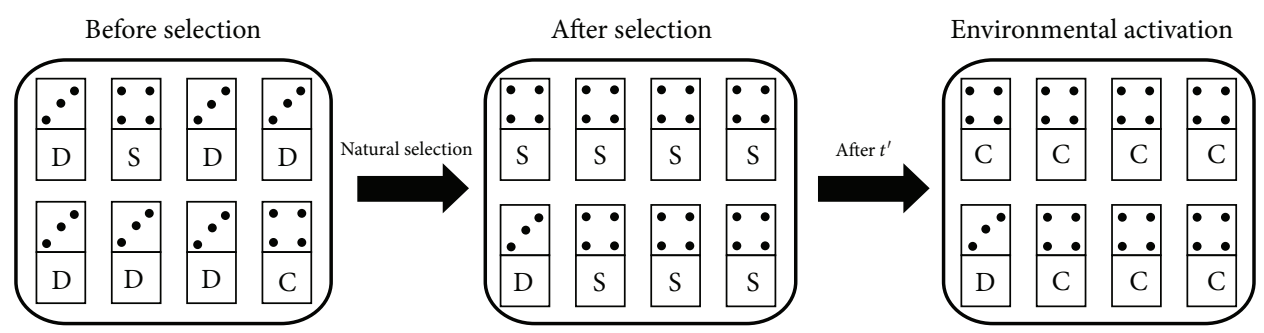

FIGURE 3: Silent genes and genetic hitchhiking: a cooperative gene in a world of defectors will be heavily exploited with no other cooperators to interact with. Hence, it has low chances of spreading in the population. A silent gene, on the other hand, does not affect its carriers' fitness till activation. And, it might hitchhike a selective sweep if it happened to be in an organism with relatively higher fitness, due to influence of the rest of the genes.

2.3. Model Description. In this paper, we adopt the spatial model from [7]; however, the main conclusions can be generalized to other models in which a critical size of cooperator clusters is needed for a successful invasion. The model from [7] consists of a $L \times L$ two-dimensional square lattice with periodic boundary conditions, where each position is occupied by a cell that can be either cooperative or defective. Each cell engages in a pairwise PD game with its neighbors. We consider the trait of taking part in a PD interaction as gene $\mathrm{Y}$, which can be either cooperative $\mathrm{C}$ or defective $D, Y \in\{C, D\}$. The payoffs of a single interaction are normalized to depend on a single parameter $u$, as shown in Table 2 [25].

The population is updated as follows: a focal cell $j$ is selected at random order. The cell interacts with all neighbor cells $b_{i}$ in its extended Moore's neighborhood of radius $r=3$, that is, all cells reached within three chess king's moves, with $i \in\left\{1,2, \ldots, N_{m}\right\} . N_{m}$ is the number of cells in Moore's neighborhood of the focal cell, with $N_{m}=(2 r+1)^{2}-1$. The fitness of cell $j$ in any generation $t, \Pi_{j}(t)$, is equal to the fitness resulting from gene $\mathrm{Y}, \pi_{j, \mathrm{Y}}(t)$, which is defined as the sum of the payoffs from the pairwise PD interactions with neighbor cells weighted according to the distance between the neighbor cell $b_{i}$ from the focal cell $a$. This can be expressed by the following equation, which is adapted from [7]:

$$
\Pi_{j}(t)=\pi_{j, \mathrm{Y}}(t)=\sum_{i=1}^{N_{m}} \frac{1}{d_{b_{i}}} E_{b_{i}}(t),
$$

with $E_{b_{i}}(t)$ as the payoff resulting from an encounter with neighbor cell $b_{i}$, which takes one of the values in Table 2 depending on the strategies of both $j$ and $b_{i} \cdot d_{b_{i}}$ is the distance between $b_{i}$ and the focal cell $j, d_{b_{i}} \in\{1,2, \ldots, r\}$. The payoffs are weighted depending on the distance as illustrated in Figure 4(a), such that the further the cell, the less the weight of its effect on a focal cell. After the fitness of all cells in the population is calculated, each cell's fitness is compared with the fitness of a random direct neighbor. As shown in Figure 4(b), for a focal cell $j$, a neighbor cell $b_{i}$ within its simple Moore's neighborhood is chosen at random. The fitness of the two cells $\Pi_{j}(t)$ and $\Pi_{b_{i}}(t)$ is compared. If cell
TABle 2: Normalized payoffs for agent $a$ against agent $b$ in a prisoner's dilemma game; $0<u<1$.

\begin{tabular}{lcc}
\hline$b$ & $\mathrm{C}$ & $\mathrm{D}$ \\
$a$ & 1 & 0 \\
$\mathrm{C}$ & $1+u$ & $u$ \\
$\mathrm{D}$ & $1+u$ \\
\hline
\end{tabular}

$j$ has higher fitness, it keeps its position, repopulating it with a cell that inherits its own gene $Y$ and has the same strategy of the parent. On the other hand, if $b_{i}$ has higher fitness, it could invade the position of $j$, repopulating it with a cell having the strategy of $b_{i}$. The probability of such invasion depends on the difference between the fitness of the two cells, expressed as follows:

$f\left(\Pi_{b_{i}}(t)-\Pi_{j}(t)\right)= \begin{cases}\frac{\Pi_{b_{i}}(t)-\Pi_{j}(t)}{k}, & \text { if } \Pi_{b_{i}}(t)>\Pi_{j}(t), \\ 0, \quad \text { otherwise, } & \end{cases}$

with $f\left(\Pi_{b_{i}}(t)-\Pi_{j}(t)\right)$ as the invasion probability and $k$ as a normalization constant such that $f\left(\Pi_{b_{i}}(t)-\Pi_{j}(t)\right) \in[0,1]$, here $k=\sum_{i=1}^{N_{m}}\left(1 / d_{b_{i}}\right)(1+u)=24(1+u)$. Using these population update rules, four extreme scenarios are shown in Figure 5. In Figure 5(b), a cooperator in a world of defectors gets a zero payoff and, in consequence, has a zero chance of invading any other cell. As explained in [7], a cluster of cooperators needs to be larger than a critical size to invade such a system. Hence, a major question is posed by such models: How could cooperation possibly emerge by rare mutations in a system dominated initially by defectors?

To address this question, we introduce two changes in the model to abstract two concepts from genetics that could offer a possible route to the emergence of cooperation in spatial systems. The first phenomenon is that genes in nature often require specific environmental factors to be active. In the absence of these environmental triggers, the gene stays unexpressed (silent), although it can be still inherited. We model this by extending the definition of gene $\mathrm{Y}$ such that it can be either cooperative $C$, defective $D$, or silent $S, Y \in\{C, D, S\}$. 


\begin{tabular}{|l|l|l|l|l|l|l|}
\hline $1 / 3$ & $1 / 3$ & $1 / 3$ & $1 / 3$ & $1 / 3$ & $1 / 3$ & $1 / 3$ \\
\hline $1 / 3$ & $1 / 2$ & $1 / 2$ & $1 / 2$ & $1 / 2$ & $1 / 2$ & $1 / 3$ \\
\hline $1 / 3$ & $1 / 2$ & 1 & 1 & 1 & $1 / 2$ & $1 / 3$ \\
\hline $1 / 3$ & $1 / 2$ & 1 & $j$ & 1 & $1 / 2$ & $1 / 3$ \\
\hline $1 / 3$ & $1 / 2$ & 1 & 1 & 1 & $1 / 2$ & $1 / 3$ \\
\hline $1 / 3$ & $1 / 2$ & $1 / 2$ & $1 / 2$ & $1 / 2$ & $1 / 2$ & $1 / 3$ \\
\hline $1 / 3$ & $1 / 3$ & $1 / 3$ & $1 / 3$ & $1 / 3$ & $1 / 3$ & $1 / 3$ \\
\hline
\end{tabular}

(a) The weights of the interactions between a focal cell and neighbor cells in an extended Moore's neighborhood of radius 3

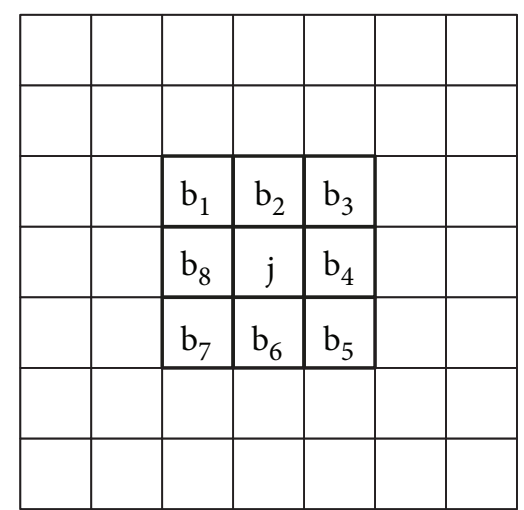

(b) A cell can have its position invaded by a randomly chosen cell from its simple Moore's neighborhood, one chess king's move from the focal cell, depending on the difference in fitness between the two cells

Figure 4: An illustration of the update rules. A focal cell plays the prisoner's dilemma game with cells in its extended Moore neighborhood; scores are weighted depending on the distance between the neighbor and the focal cell. After all cells in the grid are assigned fitness values, each cell competes with one random neighbor.

\begin{tabular}{|l|l|l|l|l|l|l|}
\hline $\mathrm{C}$ & $\mathrm{C}$ & $\mathrm{C}$ & $\mathrm{C}$ & $\mathrm{C}$ & $\mathrm{C}$ & $\mathrm{C}$ \\
\hline $\mathrm{C}$ & $\mathrm{C}$ & $\mathrm{C}$ & $\mathrm{C}$ & $\mathrm{C}$ & $\mathrm{C}$ & $\mathrm{C}$ \\
\hline $\mathrm{C}$ & $\mathrm{C}$ & $\mathrm{C}$ & $\mathrm{C}$ & $\mathrm{C}$ & $\mathrm{C}$ & $\mathrm{C}$ \\
\hline $\mathrm{C}$ & $\mathrm{C}$ & $\mathrm{C}$ & $\mathrm{C}$ & $\mathrm{C}$ & $\mathrm{C}$ & $\mathrm{C}$ \\
\hline $\mathrm{C}$ & $\mathrm{C}$ & $\mathrm{C}$ & $\mathrm{C}$ & $\mathrm{C}$ & $\mathrm{C}$ & $\mathrm{C}$ \\
\hline $\mathrm{C}$ & $\mathrm{C}$ & $\mathrm{C}$ & $\mathrm{C}$ & $\mathrm{C}$ & $\mathrm{C}$ & $\mathrm{C}$ \\
\hline $\mathrm{C}$ & $\mathrm{C}$ & $\mathrm{C}$ & $\mathrm{C}$ & $\mathrm{C}$ & $\mathrm{C}$ & $\mathrm{C}$ \\
\hline
\end{tabular}

(a) Cooperator among cooperators, focal cell

payoffs $=24$
\begin{tabular}{|l|l|l|l|l|l|l|}
\hline C & C & C & C & C & C & C \\
\hline C & C & C & C & C & C & C \\
\hline C & C & C & C & C & C & C \\
\hline C & C & C & D & C & C & C \\
\hline C & C & C & C & C & C & C \\
\hline C & C & C & C & C & C & C \\
\hline C & C & C & C & C & C & C \\
\hline
\end{tabular}

(c) Defector among cooperators, focal cell payoffs $=24(1+u)$

\begin{tabular}{|c|c|c|c|c|c|c|}
\hline $\mathrm{D}$ & $\mathrm{D}$ & $\mathrm{D}$ & $\mathrm{D}$ & $\mathrm{D}$ & $\mathrm{D}$ & $\mathrm{D}$ \\
\hline $\mathrm{D}$ & $\mathrm{D}$ & $\mathrm{D}$ & $\mathrm{D}$ & $\mathrm{D}$ & $\mathrm{D}$ & $\mathrm{D}$ \\
\hline $\mathrm{D}$ & $\mathrm{D}$ & $\mathrm{D}$ & $\mathrm{D}$ & $\mathrm{D}$ & $\mathrm{D}$ & $\mathrm{D}$ \\
\hline $\mathrm{D}$ & $\mathrm{D}$ & $\mathrm{D}$ & $\mathrm{C}$ & $\mathrm{D}$ & $\mathrm{D}$ & $\mathrm{D}$ \\
\hline $\mathrm{D}$ & $\mathrm{D}$ & $\mathrm{D}$ & $\mathrm{D}$ & $\mathrm{D}$ & $\mathrm{D}$ & $\mathrm{D}$ \\
\hline $\mathrm{D}$ & $\mathrm{D}$ & $\mathrm{D}$ & $\mathrm{D}$ & $\mathrm{D}$ & $\mathrm{D}$ & $\mathrm{D}$ \\
\hline $\mathrm{D}$ & $\mathrm{D}$ & $\mathrm{D}$ & $\mathrm{D}$ & $\mathrm{D}$ & $\mathrm{D}$ & $\mathrm{D}$ \\
\hline
\end{tabular}

(b) Cooperator among defectors, focal cell payoffs $=0$

\begin{tabular}{|c|c|c|c|c|c|c|}
\hline $\mathrm{D}$ & $\mathrm{D}$ & $\mathrm{D}$ & $\mathrm{D}$ & $\mathrm{D}$ & $\mathrm{D}$ & $\mathrm{D}$ \\
\hline $\mathrm{D}$ & $\mathrm{D}$ & $\mathrm{D}$ & $\mathrm{D}$ & $\mathrm{D}$ & $\mathrm{D}$ & $\mathrm{D}$ \\
\hline $\mathrm{D}$ & $\mathrm{D}$ & $\mathrm{D}$ & $\mathrm{D}$ & $\mathrm{D}$ & $\mathrm{D}$ & $\mathrm{D}$ \\
\hline $\mathrm{D}$ & $\mathrm{D}$ & $\mathrm{D}$ & $\mathrm{D}$ & $\mathrm{D}$ & $\mathrm{D}$ & $\mathrm{D}$ \\
\hline $\mathrm{D}$ & $\mathrm{D}$ & $\mathrm{D}$ & $\mathrm{D}$ & $\mathrm{D}$ & $\mathrm{D}$ & $\mathrm{D}$ \\
\hline $\mathrm{D}$ & $\mathrm{D}$ & $\mathrm{D}$ & $\mathrm{D}$ & $\mathrm{D}$ & $\mathrm{D}$ & $\mathrm{D}$ \\
\hline $\mathrm{D}$ & $\mathrm{D}$ & $\mathrm{D}$ & $\mathrm{D}$ & $\mathrm{D}$ & $\mathrm{D}$ & $\mathrm{D}$ \\
\hline
\end{tabular}

(d) Defector among defectors, focal cell payoffs $=24 u$

FIGURE 5: An illustration of a focal cell interacting with neighbors in its extended Moore neighborhood with range $=3$, under 4 extreme scenarios (with $u<1$ ). 
$\mathrm{S}$ aims to model the behavior of a cooperative mutation that only gets triggered after the environment reaches a favorable state for its expression (see Figure 1). This could be the result of the accumulation of a certain chemical or a certain degree of a physical parameter such as the temperature or the $\mathrm{pH}$ of the environment. Thus, $\mathrm{S}$ can be formulated as follows:

$$
\mathrm{S} \equiv \begin{cases}\mathrm{D}, & t<t^{\prime} \\ \mathrm{C}, & t>t^{\prime},\end{cases}
$$

with $t^{\prime}$ as a random variable that models the time till activation of the gene, and the equivalence symbol $\equiv$ here means "expresses the trait of". Equation (3) means that a silent gene acts as a defector, expressing the defector phenotype, till the moment when a random environmental event activates the cooperative phenotype. Hence, while the environment is not explicitly modeled here, each independent mutation could be considered to be activated by a specific state of the environment with a waiting time $t^{\prime}$. For example, if the environmental trigger that activates the silent gene is high temperatures, each independent mutation giving rise to this gene is assumed to be activated by a specific high temperature which will be realized by the environment after time $t^{\prime}$.

Hence, when a silent gene appears in a population of defectors, its carrier keeps acting as a defector. And in a world of defectors, till the gene gets expressed, it has neither negative nor positive effect on its carrier's fitness, although it can still be inherited and, in some cases, spread in the population. The second genetic phenomena to be modeled, known as genetic hitchhiking, are related to how the frequency of an unexpressed gene could increase in the population if it happened to be in the same DNA chain of another gene that is positively selected. To model the hitchhiking effect, the other modification to be introduced to the model of [7] is that the fitness of any cell $j$ in the grid, $\Pi_{j}(t)$, will not only be a result of the PD (gene Y) interactions with neighbors, but will also include another component. Hence, the fitness equation used in our model will extend (1) by including an additional fitness term as follows:

$$
\Pi_{j}(t)=\pi_{j, \mathrm{X}}(t)+\pi_{j, \mathrm{Y}}(t)
$$

with $\pi_{j, \mathrm{Y}}(t)$ as the gain in fitness resulting from the action of gene $\mathrm{Y}, \pi_{j, \mathrm{Y}}(t) \in[0,24(1+u)]$, depending on the strategy of the cell and its neighbors, calculated identically to (1). Besides, we model the gain in fitness $\pi_{j, \mathrm{X}}(t)$ resulting from the action of all other genes of the cell, aggregated as gene $\mathrm{X}$, which contribute to the cell fitness independently of the $\mathrm{PD}$ game. The initial generation of cells is assigned a base fitness due to gene $\mathrm{X}$ that is equal to zero for all cells in the population, $\pi_{j, X}(t=0)=0$, for any cell $j$ in the grid. However, each cell has a probability $P_{\mathrm{X}}(\mu)$ of a mutation in gene $\mathrm{X}$ leading to a slight increase in its fitness due to gene $\mathrm{X}, \mu$, such that for any cell $j$ in generation $t$, the fitness due to gene $\mathrm{X}$, $\pi_{j, \mathrm{X}}(t)$, is as follows:

$\pi_{j, \mathrm{X}}(t)=\left\{\begin{array}{l}\pi_{j, \mathrm{X}}(t-1), \quad \text { if no beneficial mutation occurred, } \\ \pi_{j, \mathrm{X}}(t-1)+\mu, \quad \text { if a beneficial mutation occurred. }\end{array}\right.$

In this way, gene $\mathrm{X}$ aims to model the increase in fitness of the cell resulting from any other gene rather than the one taking part in the PD game. If all cells have the same gene Y strategy, all of them are defectors or all are cooperators, a cell $j$ with higher $\pi_{j, X}(t)$ can still invade the population (see Figures 2 and 3). A flowchart of the model is presented in Figure 6 and an illustration of the fitness function is presented in Figure 7. A summary of notations used is presented in Table 3. All model simulations are executed using the Repast Simphony tool kit, an agent-based simulation platform created by [26].

\section{Results and Discussion}

In this section, we start by examining how the need for a sufficiently large cluster of cooperators hampers the possibilities of inception of cooperation in a spatial system. Next, the effects of emergence of a cooperative trait as a silent gene are explored. The rest of the section explains the biological intuition behind the results and analyses the impact of key parameters.

3.1. Emergence of Cooperation in a Biological System. First, to illustrate the problem of emergence of cooperation, we reproduce earlier results in literature by examining the effect of the initial cooperators' cluster size on their fate, with no mutations in the simulation. In Figures 8 and 9, we seed a $50 \times 50$ lattice with clusters of cooperators of sizes 9 and 25, respectively, which are cells with gene $\mathrm{Y}$ being cooperative (i.e., $\mathrm{Y}=\mathrm{C}$ ). The rest of the positions in the lattice are occupied by defectors, hence gene $\mathrm{Y}$ being defective (i.e., $\mathrm{Y}=\mathrm{D}$ ), while the value of the normalized PD variable $u$ is set to $u=0.09$. In Figures 8 and 9, the interactions among cooperators are not sufficient to compensate for the losses suffered by the exploitation from selfish agents and the cooperative gene goes extinct rapidly.

On the other hand, when starting with large cluster sizes of $6 \times 6$ and $8 \times 8$ cooperators, as shown in Figures 10 and 11, the initial cooperator population undergoes aggressive expansion at the beginning. The number of cells with $\mathrm{Y}=\mathrm{C}$ increases quadratically till it reaches a relatively stable value, around $65 \%$ of the total population. Simulations are stopped after $10^{5}$ generations. A dynamic equilibrium state is reached where compact clusters of cooperators are surrounded by stripes of defectors, in accordance with previous research $[2,7,11,27]$. These results confirm that in a spatial system, cooperators in a PD setting can dominate a world of defectors as their interactions among each other compensate losses due to encounters with cheaters. However, this will happen only if they started from a large enough initial cluster. 


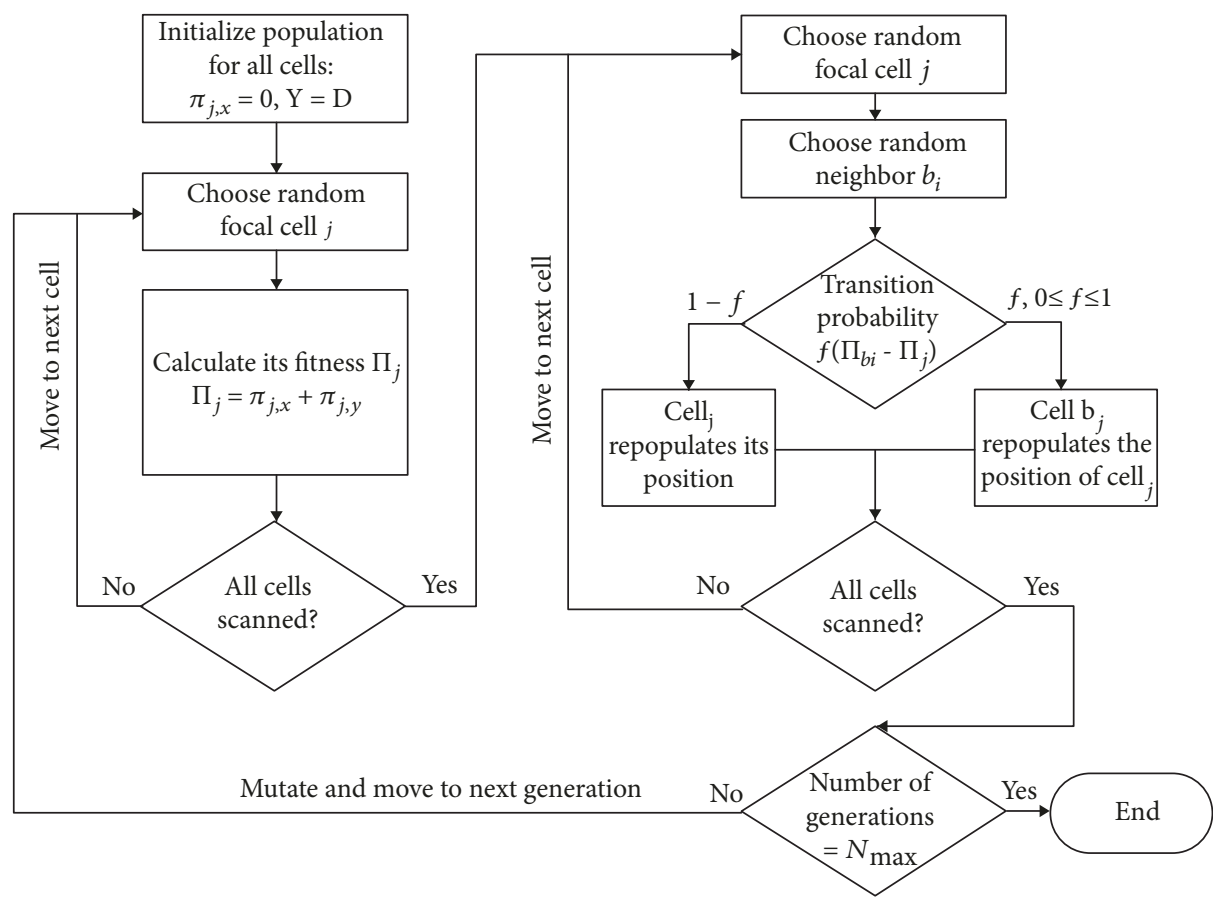

Figure 6: A flowchart of the spatial prisoner's dilemma model.

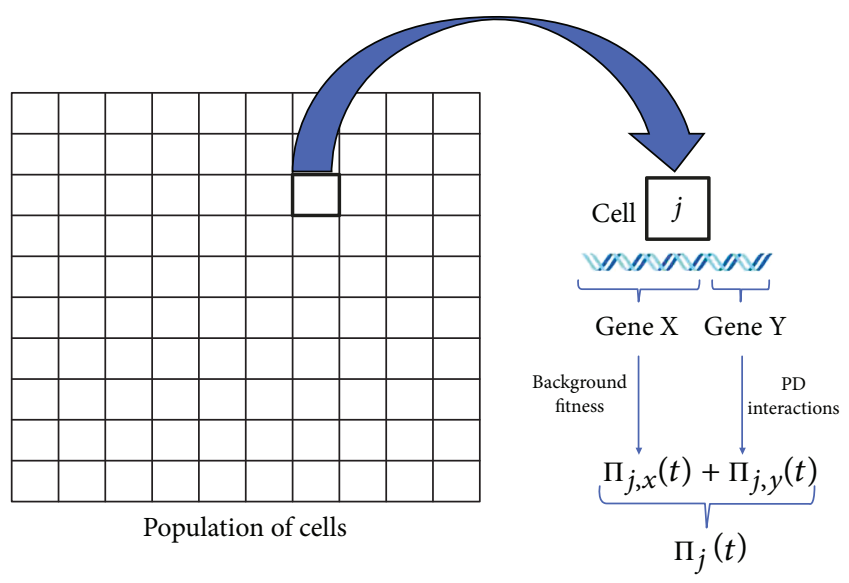

FIGURE 7: Each cell in the grid has two sources of fitness. $\pi_{j, Y}(t)$ is the familiar fitness function resulting from the PD interactions with neighbor cells. Additionally, there is $\pi_{j, \mathrm{X}}(t)$ which represents the contribution in fitness from all the other genes of the cell, aggregated as gene $\mathrm{X}$. All cells in the grid are assigned the same background fitness at the beginning of the simulation, with $\pi_{j, \mathrm{X}}(t=0)=0$ for any cell $j$ in the grid.

We proceed to study the problem of emergence of cooperation in a world of defectors. The $50 \times 50$ lattice is initialized by filling it completely with defectors, agents with $\mathrm{Y}=\mathrm{D}$, as in Figure 12(a). However, mutations are allowed to occur in the model. The probability that a cell with gene $\mathrm{Y}=\mathrm{D}$ will mutate to $\mathrm{Y}=\mathrm{C}$ is $P_{\mathrm{Y}}(\mathrm{D} \rightarrow \mathrm{C})=1 \times 10^{-4}$. Additionally, the probability of a beneficial mutation in gene $\mathrm{X}$, $P_{\mathrm{X}}(\mu)$, is set to be $P_{\mathrm{X}}(\mu)=1 \times 10^{-4}$, with $\mu=1.0$. As observed in Figures 12 and 13, the instantly expressed gene $\mathrm{Y}=\mathrm{C}$ fails to make a successful invasion of the system. This has been expected as a cooperator in a sea of defectors is very prone to exploitation as not enough interactions occur between cooperators to out-weight exploitation losses. Also, even if a cooperative mutation occurred in a cell with slightly higher $\mathrm{X}$ than its neighbors, the losses suffered from exploitation by defectors will be much larger than the gain in fitness due to gene X. Finally, the probability that cooperative mutations will coappear in a narrow spatial range such that they form a cluster of altruists is extremely small.

Do mutations of a silent cooperator gene have better chances for invading the system? We test that by allowing, with a probability of $P_{\mathrm{Y}}(\mathrm{D} \rightarrow \mathrm{S})=1 \times 10^{-4}$, that a cell with gene $\mathrm{Y}=\mathrm{D}$ will mutate into $\mathrm{Y}=\mathrm{S}$, which in turn will get activated after passing of $t^{\prime}$ generations after the mutation. For this simulation, $t^{\prime}$ is assumed to be exponentially distributed, $t^{\prime} \sim \operatorname{Exp}(\lambda)$, with a mean value of 200 generations. The simulation is again initialized by filling the lattice with defectors. In the early beginning, no cooperators at all appear, as mutations occurring in the system are still inactivated. After that, the system evolves in a way similar to the previous case of instantly expressed cooperator genes, with cooperators appearing isolated from each other and doomed to extinction. Then, after around 500 generations in this simulation, a sudden outbreak of cooperation appears with a cluster size that is large enough to eventually perform a successful invasion of the system. Thus, cooperation prevailed here. But why exactly did cooperator genes with delayed expression succeed while instantly expressed genes failed? We take a closer look at the two key features of the model which allowed these results to occur in the next section.

3.2. Silent Genes and Genetic Hitchhiking. Epigenetics refer to changes in gene expression that are not resulting from 
TABle 3: Notation system.

\begin{tabular}{|c|c|}
\hline Notation & Meaning \\
\hline$\Pi_{j}(t)$ & Fitness of cell $j$ in generation $t$ \\
\hline$\pi_{j, \mathrm{Y}}(t)$ & Fitness component of cell $j$ resulting from PD interactions \\
\hline$\pi_{j, \mathrm{X}}(t)$ & Fitness component of cell $j$ resulting from background genes, aggregated as gene $\mathrm{X}$ \\
\hline Gene Y & The trait of taking part in PD interactions; it can be either $\mathrm{C}, \mathrm{D}$, or $\mathrm{S}$ \\
\hline C & A variant of gene $\mathrm{Y}$ which always expresses cooperative behavior \\
\hline $\mathrm{D}$ & A variant of gene Y which always expresses defector's behavior \\
\hline S & A variant of gene $\mathrm{Y}$ which expresses cooperative behavior only when triggered by a future state of the environment \\
\hline$t^{\prime}$ & Time, in generations, between appearance of $S$ in the population and its activation \\
\hline Gene X & An abstraction of all genes not taking part in the PD game that contribute to the cell's fitness \\
\hline$\mu$ & $\begin{array}{c}\text { The increase in the background fitness, } \pi_{j, X}(t) \text {, of cell } j \text { due to a beneficial mutation in the background genes, unrelated } \\
\text { to the PD interactions }\end{array}$ \\
\hline
\end{tabular}

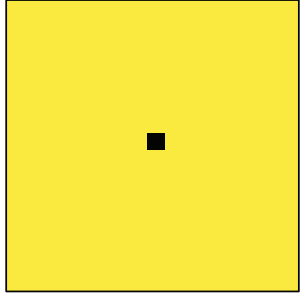

(a) Start of simulation

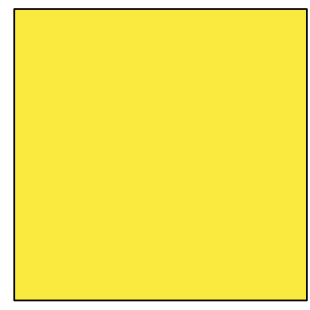

(b) End of simulation

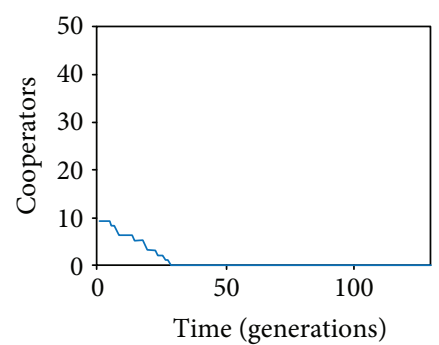

(c) Cooperator frequency

Figure 8: Evolution of cooperator frequency (black) when starting with an initial $3 \times 3$ cooperator cluster within a $50 \times 50$ grid of defectors (yellow).

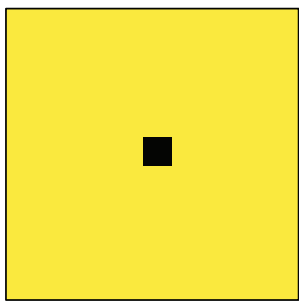

(a) Start of simulation

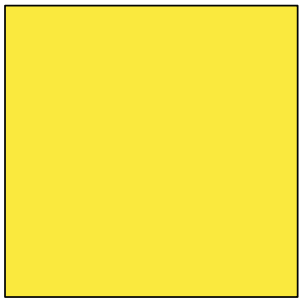

(b) End of simulation

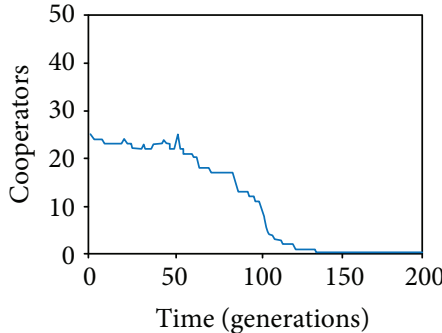

(c) Cooperator frequency

FIGURE 9: Evolution of cooperator frequency (black) when starting with an initial $5 \times 5$ cooperator cluster within a $50 \times 50$ grid of defectors (yellow).

changes in the DNA code [28]. A gene could produce a phenotype only when activated by certain environmental conditions. Also, it has been found that a gene could be tuned by an inheritance mechanism to get expressed only after a number of generations, a phenomenon known as transgenerational gene silencing $[29,30]$.

In our model, when a silent gene appears by a mutation, it remains unexpressed for a random period associated with the physical nature of each mutation. Then, after passing of $t^{\prime}$ generations, it gets activated at all cells in the system carrying this mutation. This silent interval is however essential for cooperation to break out as the gene can still spread through the population by a mechanism known as genetic hitchhiking. Genetic hitchhiking is the process by which a gene that offers no evolutionary advantage to its carrier can spread through a population due to being associated with another gene that is under a strong selection [31]. Due to this phenomenon, the frequency of a neutral gene can increase within the population if it is on the same DNA chain of another beneficial gene. In the model, mutations of gene $\mathrm{X}$ play the role of the beneficial gene. A cell with higher fitness value due to the contribution of gene $\mathrm{X}$ can slowly invade the 


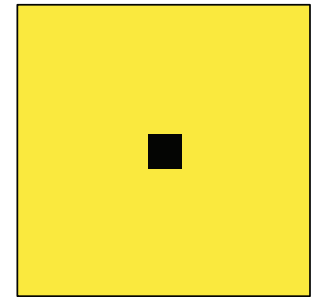

(a) Start of simulation

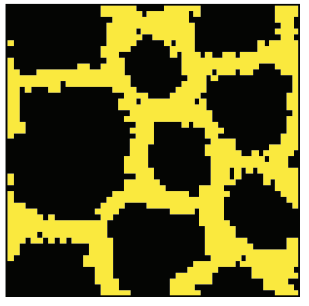

(b) End of simulation

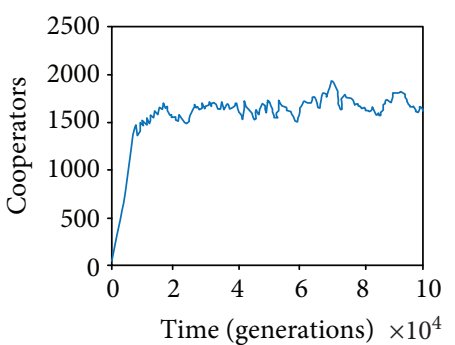

(c) Cooperator frequency

FIGURE 10: Evolution of cooperator frequency (black) when starting with an initial $6 \times 6$ cooperator cluster within a $50 \times 50$ grid of defectors (yellow).

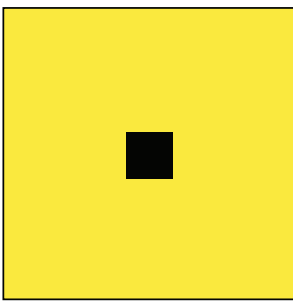

(a) Start of simulation

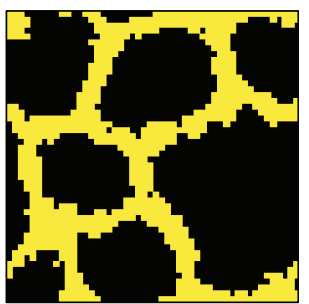

(b) End of simulation

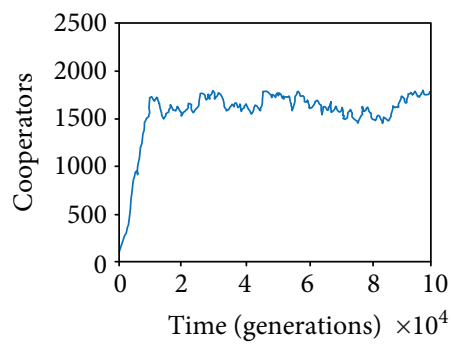

(c) Cooperator frequency

Figure 11: Evolution of cooperator frequency (black) when starting with an initial $8 \times 8$ cooperator cluster within a $50 \times 50$ grid of defectors (yellow).

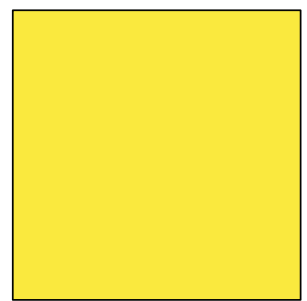

(a) Start of simulation

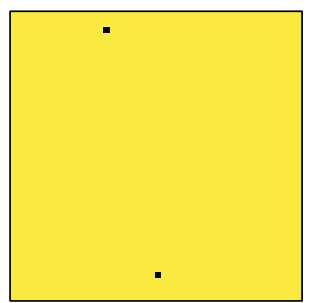

(b) After $5 \times 10^{5}$ generations

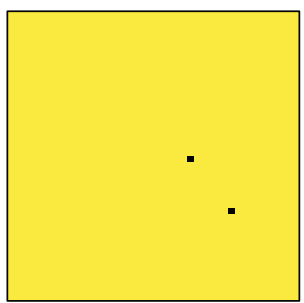

(c) End of simulation

FIGURE 12: Illustration of a system where mutations of instantly expressed cooperator genes $(\mathrm{Y}=\mathrm{C})$ occur in a $50 \times 50$ system dominated by defector genes $(\mathrm{Y}=\mathrm{D})$.

population. As illustrated in Figure 14, by combining the concepts of silent genes and genetic hitchhiking, the results of our model can be easily explained:

(i) When a mutation produces a silent cooperative trait, it will still act as a defector for a number of generations. Hence, in a world of defectors, it does not get instantly exploited.

(ii) If this mutation happened in a cell $j$ that has higher fitness due to gene $\mathrm{X}, \pi_{j, \mathrm{X}}(t)$, than its neighbors, it will spread through the population by the hitchhiking effect. If it stayed silent till the number of cells carrying the cooperative mutation exceeds a critical cluster size, it will get fixed in the population once it is expressed.

(iii) If it is expressed too early, while the number of cells carrying the cooperative mutation is still less than the critical cluster size, the damage from exploitation by defectors is most probably much higher than the relative advantage of fitness due to gene $\mathrm{X}$ and the mutation dies out.

(iv) If the mutation happened in a cell that has low or same level of gene $\mathrm{X}$ fitness compared to its neighbors, it will not spread. And when it is expressed, it will die out. 


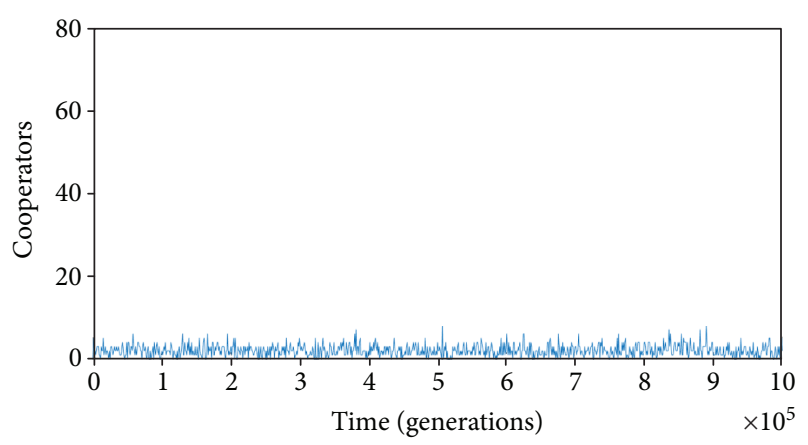

FIGURE 13: Evolution of the frequency of cooperators in a $50 \times 50$ system of defectors, where cooperation arises by instantly expressed mutations of gene $\mathrm{Y}=\mathrm{C}$.

In Figure 15, we notice that for the first 500 generations, no silent gene has been "lucky" enough to spread through the population, and so once they are expressed, they get eliminated. Then, a vertical increase in the frequency of cooperators is observed, associated with Figure 16(b). This marks the event that a silent cooperator has hitchhiked a selective sweep of gene $\mathrm{X}$ till the number of cells carrying the silent gene $\mathrm{S}$ has exceeded the critical cluster size. Cooperators expressed do not die out, and they eventually carry out a successful invasion of the lattice.

To summarize the factors influencing the emergence of altruistic traits, in a spatial biological system, the probability of a successful invasion $P_{\mathrm{I}_{\mathrm{S}}}$ for a silent cooperative gene $\mathrm{S}$ can be formulated as follows:

$$
P_{\mathrm{I}_{\mathrm{S}}}=P_{\mathrm{S}} \cdot P_{\mathrm{H}} \cdot P_{\mathrm{t}}
$$

with $P_{\mathrm{S}}$ as the probability of a mutation producing a silent cooperative gene; $P_{\mathrm{H}}$ as the probability that the organism getting the silent mutation has another gene that is going on a selective sweep, thus hitchhiking occurs; and $P_{\mathrm{t}}$ is the probability that the silent gene gets activated only after the elapse of enough time so that its spatial distribution exceeds the critical cluster size by the action of the hitchhiking effect.

On the other hand, for comparison, the probability of a successful invasion $P_{\mathrm{I}_{\mathrm{C}}}$ for an instantly expressed cooperator $C$ is

$$
P_{\mathrm{I}_{\mathrm{C}}}=P_{\mathrm{C}}{ }^{n}
$$

with $P_{\mathrm{C}}$ as the probability of a mutation producing an instantly expressed cooperative gene and $n$ as the number of cells required to exceed a critical cluster size of cooperators. If, by chance, mutations happened at the same time interval in cells very close to each other, successful invasion will occur. Hence, the larger the required cluster size for a successful invasion $n$, the more likely that $P_{\mathrm{I}_{\mathrm{C}}}<<P_{\mathrm{I}_{\mathrm{S}}}$.

Finally, it should be noted that the value used for initializing the parameter $\pi_{j, \mathrm{X}}(t=0)$, in this work, it is $\pi_{j, \mathrm{X}}(t=0)=0$ for any cell $j$ in the grid, plays absolutely no part in the results, as long as the same value is used for all the cells in the grid. That is because the invasion probability
$f\left(\Pi_{b_{i}}(t)-\Pi_{j}(t)\right)$ is a function of the difference in fitness between two neighboring cells $\left(\Pi_{b_{i}}(t)-\Pi_{j}(t)\right)$. Hence, the initial value of $\pi_{j, \mathrm{X}}(t=0)$ is not a part of the probability equation. Nonetheless, a mutation in gene $\mathrm{X}$ happening to a cell $j$ will lead to a slight increase of its fitness due to gene $\mathrm{X}, \pi_{j, \mathrm{X}}(t)$, compared to its neighbors. However, such mutations will spread in the system, and all the cells will always have very close values of fitness due to gene $\mathrm{X}$, making the PD interactions the decisive factor in the competition. In this model, the major influence of beneficial mutations in gene $\mathrm{X}$ is simulating the hitchhiking effect. Additionally, such background mutations will also lead to an interesting effect once the cooperators and defectors in the system become spatially segregated, as we will examine in the next section.

3.3. Spatial Segregation of Social Traits Is Inherently Unstable. A common feature of spatial cooperation models is that a successful invasion of a cooperative trait results in a state of dynamic equilibrium where cooperator clusters are surrounded by thin patches of defectors $[2,7,27]$. The spatial segregation happens between the two traits not due to any geographical constraints but because of the dynamics of cooperative and selfish interactions. This result makes an intuitive sense as cooperators enjoy the benefits of being surrounded by other cooperators while defectors thrive by exploiting cooperators on the borders of the clusters. So why does our model produce a different fate where the cooperative trait fully invades the system?

This is due to beneficial mutations being more likely to arise and get fixed as the population grows [32, 33]. After the initial expansion, a large population of cooperators will have higher frequency of beneficial gene $\mathrm{X}$ mutations than the small defector patches. This leads to an accumulated increase in the fitness of cooperators due to gene X compared to defectors, which in turn results in improving the chances for cooperators to expand in the system and, consequently, increase their population, thereby completing a positive-feedback loop. To examine this effect, we calculate the mean of the fitness due to gene $\mathrm{X}$ for the defectors, $\bar{\pi}_{D, \mathrm{X}}(t)$, and the cooperators, $\bar{\pi}_{\mathrm{C}, \mathrm{X}}(t)$, in this simulation, defined as follows:

$$
\begin{aligned}
& \bar{\pi}_{\mathrm{D}, \mathrm{X}}(t)=\sum_{j=1}^{n_{\mathrm{D}}(t)} \frac{\pi_{j, \mathrm{x}}(t)}{n_{\mathrm{D}}(t)}, \\
& \bar{\pi}_{\mathrm{C}, \mathrm{X}}(t)=\sum_{j=1}^{n_{\mathrm{C}}(t)} \frac{\pi_{j, \mathrm{x}}(t)}{n_{\mathrm{C}}(t)},
\end{aligned}
$$

with $n_{\mathrm{D}}(t)$ and $n_{\mathrm{C}}(t)$ as the number of cells in any generation $t$ that are expressing defector and cooperative behavior in the PD interactions, respectively. In Figure 17, as cooperative cells become dominant in the population, the rate of increase of their fitness due to gene X exceeds the defectors'. Till the end of the simulation, cooperators enjoy significantly higher gene $\mathrm{X}$ fitness, allowing them to complete a full invasion of the grid. The last defector in the system, $d$, will have $\pi_{d, \mathrm{Y}}(t)=24(1+u)$ (see Figure 5(c)). For $u=0.09$, to be 


\begin{tabular}{|c|c|c|c|c|c|c|c|c|c|c|c|}
\hline \multicolumn{6}{|c|}{$t$} & \multicolumn{6}{|c|}{$t_{f}$} \\
\hline $\mathrm{D}$ & D. & $\mathrm{D}:$ & $\mathrm{D}$ & $\mathrm{D}$ & $\mathrm{D}$ & D & $\mathrm{D}$ & $D$ & $\mathrm{D}$ & $\mathrm{D}$ & $\mathrm{D}$ \\
\hline $\mathrm{D}$ & $\mathrm{D}$ & $D$ & $D$ & $\mathrm{D}$ & $\mathrm{D}$ & $D$ & $\mathrm{D}$ & $D$ & $\mathrm{D}$ & $\mathrm{D}$ & $\mathrm{D}$ \\
\hline $\mathrm{D}$ & $\mathrm{D}$ & C & $\mathrm{D}$ & $\mathrm{D}$ & $\mathrm{D}$ & $\because \mathrm{D}$ & $D$ & $D$ & $\therefore$ & $\mathrm{D}$ & $\mathrm{D}$ \\
\hline $\mathrm{D}$ & $\mathrm{D}$ & $\mathrm{D}$ & $\mathrm{D}$ & $\therefore$ & $\dot{\mathrm{D}}$ & $D$ & $D$ & $\mathrm{D}$ & $\therefore$ & $\therefore$ & $\dot{\mathrm{D}}$ \\
\hline $\mathrm{D}$ & $\mathrm{D}$ & $\mathrm{D}$ & $\mathrm{D}$ & $\mathrm{D}$ & $\mathrm{D}$ & $\mathrm{D}$ & $D$ & $\mathrm{D}$ & $\because$ & $\mathrm{D}$ & D. \\
\hline $\mathrm{D}$ & $\mathrm{D}$ & $\mathrm{D}$ & $\mathrm{D}$ & $\mathrm{D}$ & $\mathrm{D}$ & $\mathrm{D}$ & $\mathrm{D}$ & $\mathrm{D}$ & $\mathrm{D}$ & $\triangle \mathrm{D}$ & $D$ \\
\hline
\end{tabular}

(a) Case 1: a mutation resulting in an instantly expressed cooperative trait, $\mathrm{Y}=\mathrm{C}$, gets heavily exploited in a world of defectors and most probably dies out, even if it occurred in a cell with higher gene $\mathrm{X}$ fitness than its neighbors

\begin{tabular}{|c|c|c|c|c|c|c|c|c|c|c|c|c|c|c|c|c|c|}
\hline \multicolumn{6}{|c|}{$t$} & \multicolumn{12}{|c|}{$t^{\prime}$} \\
\hline$\triangle \mathrm{B}$ & $\triangle$ & $\mathrm{B}$ & $D$ & $D$ & $D$ & $D$ & $\triangle \mathrm{B}$ & $\mathrm{B}$ & $\mathrm{D}$ & $D$ & $D$ & $D$ & $\mathrm{D}$ & $\dot{\mathrm{D}}$ & 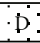 & $\mathrm{D}$ & $D$ \\
\hline $\mathrm{D}$ & p. & D. & $\mathrm{p}$ & $\dot{D}$ & $\dot{\mathrm{D}}$ & D. & $\mathrm{D}$ & pi & $p$ & $\mathrm{D}$ & $\dot{D}$ & $\dot{D}$ & $\mathrm{D}$ & $\dot{\mathrm{D}}$ & $\mathrm{D}$ & $\dot{D}$ & $D$ \\
\hline$\dot{D}$ & $\cdot \dot{\mathrm{D}}$ & $\dot{\mathrm{s}}$ & -D & $\mathrm{D}$ & $\mathrm{D}$ & $\therefore$ & $\therefore$ & $\dot{s}$ & - D & D. & $\mathrm{D}$ & $\mathrm{D}$ & $\mathrm{D}$ & is: & $D$ & $\dot{D}$ & $\therefore$ \\
\hline$\dot{\mathrm{D}}$ & $\dot{\mathrm{D}}$ & $\dot{\mathrm{D}}$ & $\dot{\mathrm{D}}$ & $\ddot{D}$ & $D$ & $\ddot{\mathrm{D}}$ & $\dot{\mathrm{D}}$ & $\dot{\mathrm{B}}$ & $\ddot{D}$ & $\ddot{D}$ & $D$ & $\mathrm{D}$ & $\mathrm{D}$ & $\mathrm{D}$ & $D$ & $D$ & $\ddot{D}$ \\
\hline $\mathrm{D}$ & D. & $D$ & D & $\mathrm{D}$ & $D$ & $\mathrm{D}$ & D. & D. & $D$ & $D$ & $\mathrm{D}$ & $\therefore \dot{D}$ & $\dot{\mathrm{D}}$ & $\dot{\mathrm{D}}$ & $\dot{D}$ & D. & $D$ \\
\hline$\therefore$ & $\dot{\mathrm{D}}$ & $\cdot \dot{D}$ & $\cdot \dot{D}$ & D: & $\mathrm{D}$ & $\therefore \dot{D}$ & $\therefore$ & $\dot{D}$ & $\mathrm{D}$ & D: & $\mathrm{D}$ & $\mathrm{D}$ & $\triangle$ & DD & $D$ & $D \cdot$ & $\because \dot{D}$ \\
\hline
\end{tabular}

(b) Case 2: a mutation resulting in a silent trait, $\mathrm{Y}=\mathrm{S}$, and the cell carrying the mutation still acts as a defector, $\mathrm{S} \equiv \mathrm{D}$, till time $t^{\prime}$ after the mutation. Then, it expresses the cooperative behavior, $\mathrm{S} \equiv \mathrm{C}$. Here, the silent gene did not spread, and it will die out once it is expressed, similar to Case 1

\begin{tabular}{|c|c|c|c|c|c|c|c|c|c|c|c|c|c|c|c|c|c|}
\hline \multicolumn{6}{|c|}{$t$} & \multicolumn{12}{|c|}{$t^{\prime}$} \\
\hline$\dot{p}$ & $\dot{\mathrm{D}}$ & $\dot{\mathrm{D}}$ & $\dot{\mathrm{D}}$ & $\dot{\mathrm{D}}$ & $\dot{D}$ & $\dot{\mathrm{D}}$ & $\dot{D}$ & $\mathrm{D}$ & $\mathrm{D}$ & $\mathrm{D}$ & $\mathrm{p}$ & $\dot{\mathrm{B}}$ & $\dot{\mathrm{D}}$ & $\dot{\mathrm{D}}$ & $\dot{D}$ & D. & $\mathrm{D}$ \\
\hline D & $\mathrm{D}$ & D: & D. & DD & $D$ & D. & $\mathrm{s}$ & $\mathrm{s}$ & $\mathrm{S}$ & $\dot{\mathrm{D}}$ & $\dot{\mathrm{D}}$ & D. & $s$ & $\mathrm{~s}$ & $\mathrm{~S}$ & $\therefore$ & $\dot{\mathrm{D}}$ \\
\hline$D$ & $D$ & $\mathrm{~s}$ & $\mathrm{D}$ & $\mathrm{D}$ & $D$ & s & $\mathrm{s}$ & $s$ & $s$ & $\dot{\mathrm{B}}$ & $\dot{\mathrm{B}}$ & $S$ & $s$ & $\mathrm{~s}$ & $s$ & $\mathrm{D}$ & $\mathrm{D}$ \\
\hline $\mathrm{D}$ & $\dot{D}$ & $\dot{D}$ & $\dot{\mathrm{D}}$ & $\dot{\mathrm{D}}$ & $\dot{\mathrm{D}}$ & $\mathrm{s}$ & $s$ & $\mathrm{~s}$ & $D$ & D. & $\triangle \mathrm{D}$ & $s$ & $s$ & $\mathrm{~S}$ & $\dot{D}$ & D. & $\mathrm{D}$ \\
\hline D & $\dot{D}$ & $\mathrm{D}$ & D. & $\because$ & $\therefore$ & $s$ & $s$ & $s$ & $\therefore$ & $\dot{D}$ & $\dot{\mathrm{D}}$ & $\mathrm{s}$ & $\mathrm{s}$ & $\mathrm{s}$ & $D$ & $\therefore$ & $\because \overline{\mathrm{D}}$ \\
\hline$D$ & $D$. & D & $\mathrm{D}$ & $\mathrm{D}$ & $D$ & $\mathrm{D}$ & $D$ & $p$ & $\dot{\mathrm{B}}$ & $\therefore$ & $\therefore$ & $\mathrm{DD}$ & $\mathrm{p}$ & $D$ & $p$ & $\dot{\mathrm{D}}$ & $\dot{\mathrm{B}}$ \\
\hline
\end{tabular}

(c) Case 3: a mutation resulting in a silent trait, $\mathrm{Y}=\mathrm{S}$, that happened to be on a cell with higher background fitness (gene $\mathrm{X}$ fitness) than its neighbors. The mutation spreads in the system via hitchhiking, and if it gets activated after exceeding a critical cluster size, it stays in the system

Figure 14: An illustration of the different scenarios for emergence of a cooperative behavior in a world of defectors in the model. The dot density here represents the background fitness (gene X fitness) of a cell.

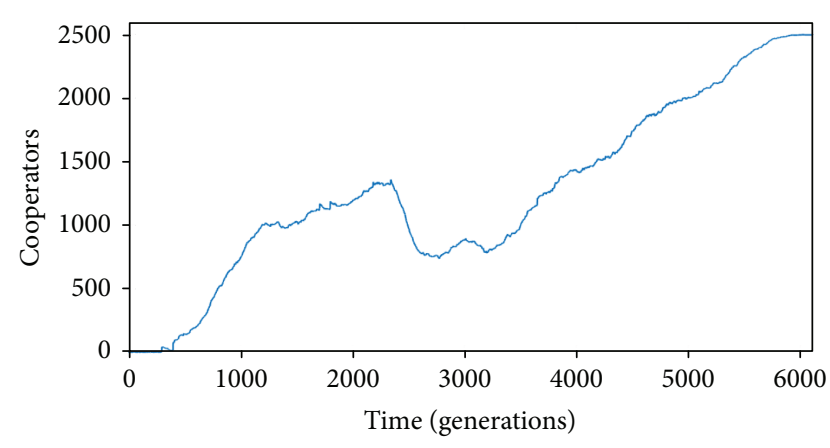

Figure 15: Evolution of the frequency of cooperators in a $50 \times 50$ system of defectors, where cooperation arises by silent mutations of gene $\mathrm{Y}=\mathrm{S}$.

invaded by a neighbor cooperator $b_{i}$ with $\pi_{b_{i}, \mathrm{Y}}(t)=23$, the difference in $\bar{\pi}_{\mathrm{D}, \mathrm{X}}(t)$ and $\bar{\pi}_{\mathrm{C}, \mathrm{X}}(t)$ will always approach 3 by the end of the simulation.
It has to be stressed though that this result of a total invasion by the cooperative trait of the system cannot be used to draw general conclusions about the stability of cooperative traits in spatial systems. Since the model is concerned mainly with the problem of emergence of cooperation through rare mutations in a system dominated by defectors, only mutations giving rise to cooperative genes have been considered. In reality, it is likely that mutations can go in both directions, which will generally affect the stability of the cooperative trait in the system depending on the rates of mutations in both directions. The interested reader could refer to the works of $[34,35]$ for an analysis of this subject.

Next, we explore the effects of the activation time of the silent gene, $t^{\prime}$, and the gain in fitness due to gene $\mathrm{X}$ mutations, $\mu$, on the invasion time of the altruistic trait. To get established in a system, a silent cooperative mutation has to spread via hitchhiking a beneficial mutation, to the extent that when it gets activated, a cooperator cluster larger than the critical size appears. Therefore, the faster a silent 


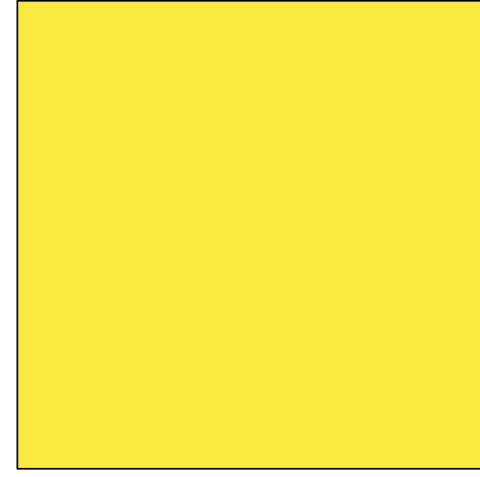

(a) Start of simulation

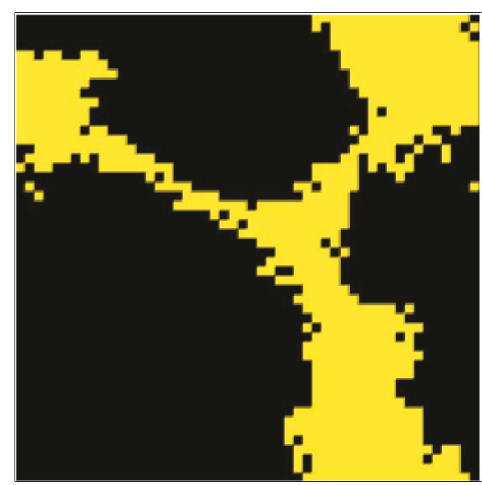

(c) After 4500 generations

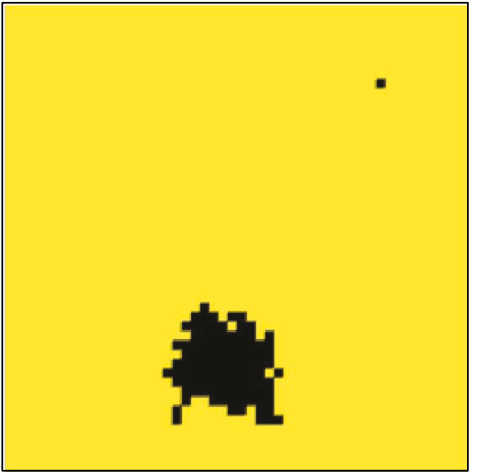

(b) After 500 generations

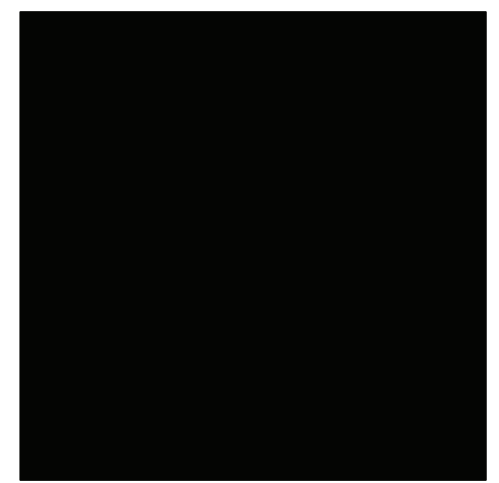

(d) End of simulation

FIGURE 16: Illustration of a system where mutations of silent cooperator genes $(\mathrm{Y}=\mathrm{S})$ occur in a $50 \times 50$ system dominated by defector genes $(Y=D)$. Silent genes get activated later at a random point of time $t^{\prime}$ to express the cooperative trait.

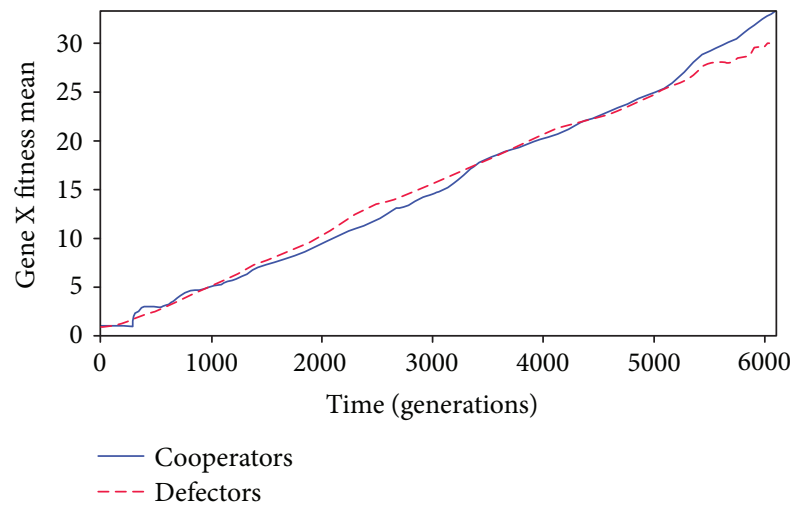

Figure 17: Evolution of the mean of fitness due to gene $\mathrm{X}$ for cooperators and defectors during the simulation.

mutation gets activated, the less likely that its spatial distribution allows it to invade the system. Also, if the propagation of beneficial mutations is slow within the system, a silent mutation is more likely to get activated before its concentration at a region in the grid reaches the required threshold. The next two sections explore the impact of $t^{\prime}$ and $\mu$ on the invasion dynamics in the simulation.

3.4. Effect of Activation Time. Activation time $t^{\prime}$ refers here to how many generations the silent cooperative gene will stay unexpressed. In reality, this could depend on the rarity, or

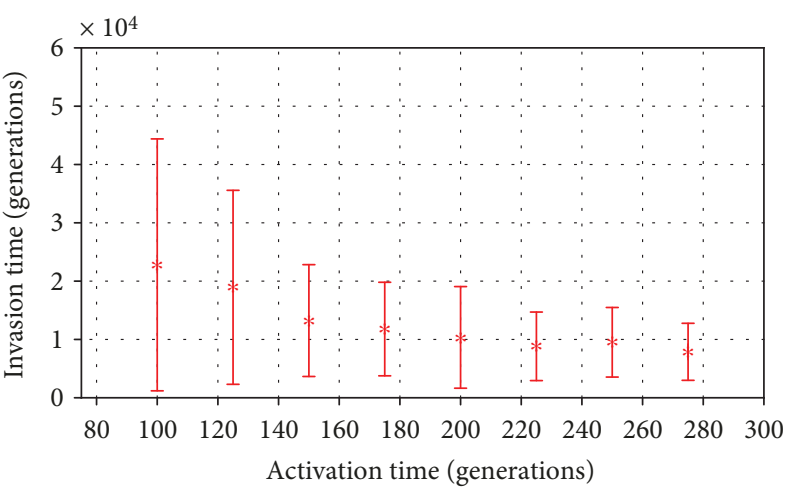

FIgURE 18: Relationship between invasion time of a silent cooperative gene and the length of its activation time. For every value of the activation time, the simulation has been run 100 times and the invasion time mean has been calculated. The vertical bars represent the standard deviation of the results.

the severity, of the environmental events that could lead to the activation of a particular cooperative mutation. As observed in Figure 18, at low activation times, the invasion time of the cooperative trait is high. When using $t^{\prime}=80$ generations, $11 \%$ of the simulations did not even reach equilibrium within $10^{5}$ generations. This number increased to $72 \%$ and $100 \%$ at $t^{\prime}=40$ and $t^{\prime}=0$, respectively. On the other hand, as the activation time increases, the invasion time 


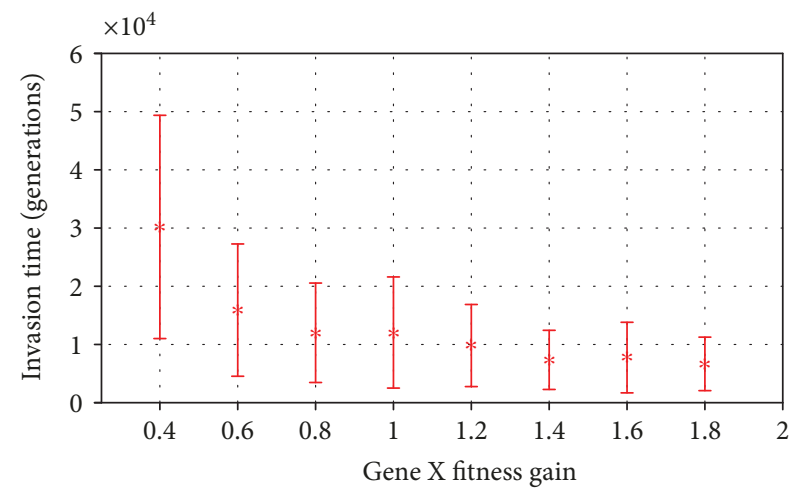

Figure 19: Relationship between invasion time of a silent cooperative gene and the magnitude of the gain in fitness due to gene $\mathrm{X}$ mutations. For every value of gene $\mathrm{X}$ gain, the simulation has been run 100 times and the invasion time mean has been calculated. The vertical bars represent the standard deviation of the results.

decreases. This is a consequence of the fact that the survival of a cooperative mutation rests on it remaining unexpressed, thus increasing its chances of spreading through the population via hitchhiking till it exceeds the critical cluster size. For a certain critical cluster size, this effect becomes less strong as the activation time becomes excessively long.

3.5. Effect of Gene X Gain. The second factor that influences the outbreak of a silent cooperative gene via hitchhiking is the speed by which beneficial mutations spread within the system. This will depend on the magnitude of the increase in fitness induced by a mutation and the frequency of interactions between the cells. We study how the change in the fitness gain resulting from gene $\mathrm{X}$ mutations, $\mu$, affects the invasion time of the silent cooperative gene. In Figure 19, it is shown that at low values of $\mu$, resulting in slow selective sweeps, the invasion time is high. When using $\mu=0.2$ and $\mu=0,79 \%$ and $100 \%$, respectively, of the simulations did not reach a successful invasion of the cooperative trait within $10^{5}$ generations. If beneficial mutations spread slowly within the system, chances are higher that the hitchhiking silent genes will get expressed before reaching a critical distribution which allows it to perform a successful invasion. The higher the $\mu$, the faster genes spread through the population and the lower the invasion time. This effect becomes weaker as $\mu$ increases, for fixed activation time and critical cluster size.

A parameter map visualizing the effects of varying the two parameters on the rate of successful invasions is presented in Figure 20.

3.6. Effect of Moore's Neighborhood Radius. Biological systems are characterized by their spatial diffusivity, as the effects of interactions between an organism and its neighbors depend on the distance between them. For example, when a living cell shares public good, the surrounding cells benefit from it in different degrees, depending on their distance to the focal cell and the diffusivity of the system. A system with low spatial diffusivity, where cells interact exclusively with their direct neighbors, is expected to offer higher chances

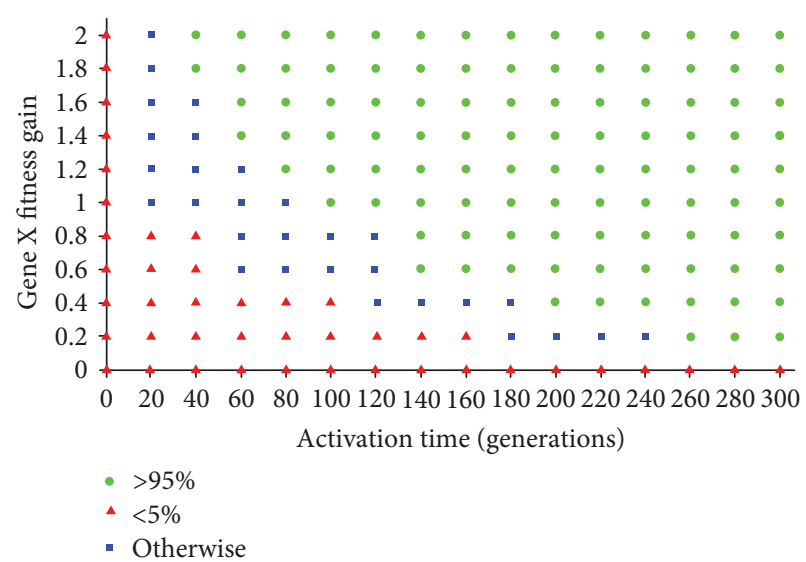

FIgURE 20: Rate of successful invasions within $10^{5}$ generations in 20 simulations, for different combinations of activation time and gene $\mathrm{X}$ gain.

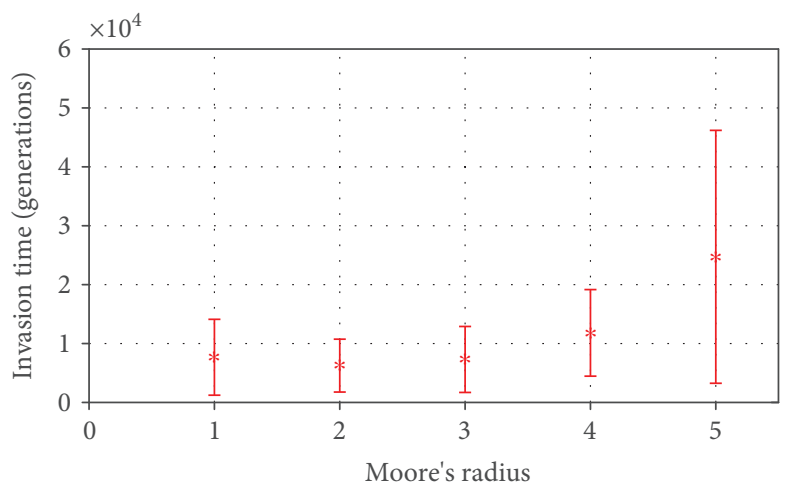

FIgURE 21: Relationship between invasion time of a silent cooperative gene and Moore's neighborhood radius. Simulations are run for 100 times for each point with the vertical bars representing the standard deviation.

for emergence of cooperation than systems with high interaction radius, as a smaller initial cluster of cooperators is needed for cooperation to emerge. Here, this effect is investigated by varying the Moore's neighborhood radius $r$ in the simulations. As shown in Figure 21 for fixed parameter values of $t^{\prime}=240$ and $\mu=1.4$, the invasion time mean increases as the neighborhood radius increases. A higher neighborhood radius means that the silent gene is more likely to get activated before spreading enough in the system for cooperation to be stable. For comparison, simulations were also carried out for instantly expressed cooperative mutations. For $r=1,29 \%$ of the simulations resulted in successful invasions of the cooperative trait within $10^{5}$ generations. This ratio has dropped to only 5\% for $r=2$ and $0 \%$ for larger neighborhood radii. Emergence of cooperation in both cases is significantly easier for smaller values of Moore's neighborhood radius. However, as $r$ increases, it becomes more difficult for cooperation to emerge by a relatively high number of instantly expressed mutations occurring in close proximity in time and space. 
We end this section with a short discussion of how silent cooperative genes can influence our understanding of natural selection.

3.7. Selection for Quietness. In [11], it is shown that cooperation can be stable in the setting of spatial PD interactions. Reference [7] has constructed a similar model in order to investigate the invasion dynamics of a cooperative trait in spatial PD and snowdrift games. There, it has been shown that in the case of the PD game, the model reaches a state of spatial segregation between cooperators and defectors with cooperators breaking up into isolated clusters in order to reduce the exploitation effects from defectors. In Section 3.3 , we have shown that including the occurrence of background beneficial mutations into the model leads to the instability of the spatial segregation between traits at the long term. More importantly, a common feature in the works of $[2,7]$ is that for a cooperative trait to survive and expand in the system, a critically sized cluster of cells carrying this trait has to exist at the beginning. Both works have thoroughly investigated the invasion dynamics, the stability of a cooperative trait, and the resulting spatial patterns in spatial PD systems. This paper focuses on the problem of how an initial cluster of cooperators could appear by random mutations in the first place.

Our model showed that the delayed expression of a cooperative gene could improve its chances of a successful invasion. Also, the longer the time till switching on the gene, the better. Similar observations have been made by [16] when studying how quorum sensing can enable a cooperative bacterial strain to dominate a biofilm, by delaying the expression of the cooperative gene till enough segregation occurs. Furthermore, it has been shown that in case of strong competition (highly mixed biofilms), only bacterial strains with a high quorum-sensing threshold can dominate the biofilm as segregation occurs later in time. Natural selection in this case selects for the strains that delay expression of their cooperative trait.

In a general setting, the larger the critical size of a cooperator cluster required for a successful invasion, the stronger the need for a delayed expression of the cooperator gene. In other words, natural selection here acts to select the cooperative genes which require more aggressive change in the environment to be expressed.

A typical view of natural selection is that it acts on the currently expressed phenotypes. We fix a point in time, and we look at the genes expressing phenotypes that have higher fitness compared to their alleles. Based on that, one can predict that the frequency of those more adapted alleles will increase in the environment as the biological system evolves. On the other hand, natural selection, in our work and in [16], selects genes not on their expressed phenotypes but on their ability to not express them. That is, it favors genes that have devised the most devious ways to endure a possibly long hitchhiking trip.

\section{Conclusion}

Cooperation plays a central role in countless biological phenomena, and explaining its emergence and preservation in living systems remains a major challenge. Spatial competition dynamics have provided an intuitive answer to the problem of how cooperation can persist in a biological system. Since individuals are more likely to interact with their neighbors, cooperative cells in a spatial PD game can dominate the system by existing in clusters. Consequently, the high frequency of mutually beneficial interactions among altruists can balance the exploitation by defectors on the boundaries of the cooperative segments. This explanation however leads us to consider the fundamental problem of the lonely cooperator. Rare mutations producing individuals with simple cooperative traits, not involving memory or communication, in a system dominated by defectors are doomed to extinction, as they are prone to heavy exploitation by their neighbors. In hostile environments, emergence of such traits is highly unlikely.

In this paper, we propose the idea that silent genes could provide a route for emergence of cooperation in biological systems. A silent mutation is one that does not get immediately expressed. Instead, it only gets activated at a random point of the future, possibly due to specific environmental conditions. A rare mutant carrying a silent cooperative trait will still act as a defector, making it safe from exploitation, till its latent altruistic trait gets activated. Subsequently, a silent gene has a chance to spread through the biological system, which occurs in our model by hitchhiking to another beneficial gene under positive selection. Afterwards, when a change in environment happens that can trigger this specific mutation, cells carrying this gene could happen to exist in the required spatial distribution to survive, and even invade, the system. In short, two established genetic concepts, silent genes and genetic hitchhiking, could explain how a simple cooperative trait emerges in a biological system.

It is also interesting to note that our model suggests that spatial segregation between social traits, an equilibrium state frequently produced by spatial cooperation models, could be evolutionary unstable. Two types of the same organism which are spatially segregated and genetically identical except in a single social trait can be assumed to have the same mutation frequency. Since the rate of beneficial mutations in a population of any type is proportional to its size, and the population size itself expands as the fitness of its individuals increases, the coexistence of two competing simple social traits in a biological system is bound to be an unstable equilibrium point. That said, it has to be emphasized that the fourth-mentioned result is qualified by the noninclusion of mutations giving rise to the defector trait in the model, which will significantly affect the general problem of the stability of cooperation in biological systems. Additionally, it should be also highlighted that this model did not include background deleterious mutations; $\mu$ is always positive. However, this will not affect the results as such mutations will not spread in the system. Only beneficial mutations play a significant role as they carry out the hitchhiking process. Also, it is assumed in this work that when the environment reaches a state that could trigger a silent gene, it gets synchronously activated in all the organisms carrying it in the population. This is clearly a simplifying assumption. In reality, the environment never changes at exactly the same 
degree for all the population. Nevertheless, it is natural to expect that organisms which are spatially close to each other will experience similar environmental conditions. This could be enough for cooperation to emerge as the trait needs to be expressed only by a cluster of organisms at the same time interval to be stable.

Finally, we would like to highlight that in the model presented in this paper, for simplicity, genes are assumed to only transfer vertically, from a single parent to a single offspring. In real life, genes will also transfer horizontally. In bacteria, this happens by the means of horizontal gene transfer, and in sexual organisms, this happens by the process of sexual reproduction. Hence, for a silent mutation to hitchhike a gene undergoing a selective sweep, it needs to be physically close to the beneficial gene on the DNA. It has been shown that hitchhiking events can be detected via statistical analysis of genetic variation along chromosomes [36]. Therefore, when considering real-life situations, our model predicts that cooperative genes are more likely to be close in the DNA chain to "competitive" genes, ones that may have gone through a selective sweep in the past, than being close to other cooperative/public good genes or silent segments of the DNA.

\section{Conflicts of Interest}

The authors declare that the research was conducted in the absence of any commercial or financial relationships that could be construed as a potential conflict of interest.

\section{Acknowledgments}

The authors would like to thank two anonymous reviewers for comments that helped to improve and clarify this manuscript. I. Hashem is supported by FWO-SB Grant 1S54217N. This work was supported by Project PFV/10/002 (Center of Excellence OPTEC-Optimization in Engineering) of the KU Leuven Research Fund, Project G.0930.13 of the Fund for Scientific Research Flanders, and the Belgian Program on Interuniversity Poles of Attraction, initiated by the Belgian Federal Science Policy Office (IAP Phase VII/19 DYSCO).

\section{References}

[1] A. Gardner, A. S. Griffin, and S. A. West, Theory of Cooperation, John Wiley and Sons, Ltd, 2001.

[2] M. A. Nowak and R. M. May, "The spatial dilemmas of evolution," International Journal of Bifurcation and Chaos, vol. 3, no. 1, pp. 35-78, 1993.

[3] P. E. Turner and L. Chao, "Prisoner's dilemma in an RNA virus," Nature, vol. 398, no. 6726, pp. 441-443, 1999.

[4] J. West, Z. Hasnain, J. Mason, and P. K. Newton, “The prisoner's dilemma as a cancer model," 2015, http://arXiv.org/ abs/1512.04591.

[5] G. Lambert, S. Vyawahare, and R. H. Austin, "Bacteria and game theory: the rise and fall of cooperation in spatially heterogeneous environments," Interface Focus, vol. 4, no. 4, 2014.

[6] R. I. Wood, J. Y. Kim, and G. R. Li, "Cooperation in rats playing the iterated prisoner's dilemma game," Animal Behaviour, vol. 114 , pp. 27-35, 2016.
[7] F. Fu, M. A. Nowak, and C. Hauert, "Invasion and expansion of cooperators in lattice populations: prisoner's dilemma vs. snowdrift games," Journal of Theoretical Biology, vol. 266, no. 3, pp. 358-366, 2010.

[8] W. Gang, G. Kun, Y. Han-Xin, and W. Bing-Hong, "Role of clustering coefficient on cooperation dynamics in homogeneous networks," Chinese Physics Letters, vol. 25, no. 6, pp. 2307-2310, 2008.

[9] K. Lindgren and M. G. Nordahl, "Evolutionary dynamics of spatial games," Physica D: Nonlinear Phenomena, vol. 75, no. 1-3, pp. 292-309, 1994.

[10] B. Allen, J. Gore, and M. A. Nowak, "Spatial dilemmas of diffusible public goods," eLife, vol. 2, 2013.

[11] M. A. Nowak and R. M. May, "Evolutionary games and spatial chaos," Nature, vol. 359, no. 6398, pp. 826-829, 1992.

[12] M. Archetti and I. Scheuring, "Review: game theory of public goods in one-shot social dilemmas without assortment," Journal of Theoretical Biology, vol. 299, pp. 9-20, 2012.

[13] D. Helbing, Social Self-Organization: Agent-Based Simulations and Experiments to Study Emergent Social Behavior, Springer, Berlin, NY, USA, 2012.

[14] N. Barraud, S. Kjelleberg, and S. Rice, "Dispersal from microbial biofilms," Microbiology Spectrum, vol. 3, no. 6, 2015.

[15] J.-U. Kreft, "Biofilms promote altruism," Microbiology, vol. 150, no. 8, pp. 2751-2760, 2004.

[16] J. Schluter, A. P. Schoech, K. R. Foster, and S. Mitri, "The evolution of quorum sensing as a mechanism to infer kinship," PLoS Computational Biology, vol. 12, no. 4, article e1004848, 2016.

[17] B. Atkinson and D. Walden, Changes in Eukaryotic Gene Expression in Response to Environmental Stress, Cell BiologyAcademic Press. Academic Press, 1985.

[18] G. Gibson, "The environmental contribution to gene expression profiles," Nature Reviews Genetics, vol. 9, no. 8, pp. 575$581,2008$.

[19] A. H. Sturtevant, "The Himalayan rabbit case, with some considerations on multiple allelomorphs," The American Naturalist, vol. 47, no. 556, pp. 234-239, 1913.

[20] W. A. Silverman, "A cautionary tale about supplemental oxygen: the albatross of neonatal medicine," Pediatrics, vol. 113, no. 2, pp. 394-396, 2004.

[21] E. R. Olson, "Influence of $\mathrm{pH}$ on bacterial gene expression," Molecular Microbiology, vol. 8, no. 1, pp. 5-14, 1993.

[22] S. Huang, M. Litt, and C. Blakey, Epigenetic Gene Expression and Regulation. Translational Epigenetics Series, Elsevier Science \& Technology Books, 2015.

[23] J. M. Smith and J. Haigh, "The hitch-hiking effect of a favourable gene,” Genetics Research, vol. 23, no. 1, pp. 23-35, 1974.

[24] S. Brenner, J. Miller, and W. Broughton, Encyclopedia of Genetics. No. v. 3 in Encyclopedia of Genetics, Academic Press, 2002.

[25] M. Doebeli and C. Hauert, "Models of cooperation based on the prisoner's dilemma and the snowdrift game," Ecology Letters, vol. 8, no. 7, pp. 748-766, 2005.

[26] M. J. North, N. T. Collier, J. Ozik et al., "Complex adaptive systems modeling with Repast Simphony," Complex Adaptive Systems Modeling, vol. 1, no. 1, p. 3, 2013.

[27] M. P. Nguyen and K. Lindgren, "Irregular spatial prisoners dilemma and the evolution of cooperation," 2013. 
[28] V. E. A. Russo, Epigenetic Mechanisms of Gene Regulation, Cold Spring Harbor Laboratory Press, Plainview, NY, USA, 1996.

[29] L. Houri-Ze'evi, Y. Korem, H. Sheftel et al., "A tunable mechanism determines the duration of the transgenerational small RNA inheritance in C. elegans," Cell, vol. 165, no. 1, pp. 88-99, 2016.

[30] D. Qutob, B. Patrick Chapman, and M. Gijzen, "Transgenerational gene silencing causes gain of virulence in a plant pathogen," Nature Communications, vol. 4, no. 1, p. 1349, 2013.

[31] J. H. Gillespie, "Genetic drift in an infinite population: the pseudohitchhiking model," Genetics, vol. 155, no. 2, pp. 909919, 2000.

[32] X. Jiang, B. Mu, Z. Huang, M. Zhang, X. Wang, and S. Tao, "Impacts of mutation effects and population size on mutation rate in asexual populations: a simulation study," BMC Evolutionary Biology, vol. 10, no. 1, p. 298, 2010.

[33] O. K. Silander, O. Tenaillon, and L. Chao, "Understanding the evolutionary fate of finite populations: the dynamics of mutational effects," PLoS Biology, vol. 5, no. 4, article e94, 2007.

[34] J. M. Epstein, "Zones of cooperation in demographic prisoner's dilemma," Complexity, vol. 4, no. 2, 48 pages, 1998.

[35] G. Ichinose, Y. Satotani, and H. Sayama, "How mutation alters fitness of cooperation in networked evolutionary games," 2017, http://arXiv.org/abs/1706.03013.

[36] Y. Kim and W. Stephan, "Detecting a local signature of genetic hitchhiking along a recombining chromosome," Genetics, vol. 160, no. 2, pp. 765-777, 2002. 


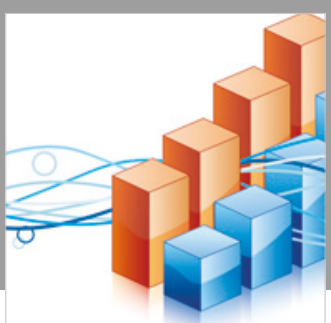

Advances in

Operations Research

\section{-n-m}
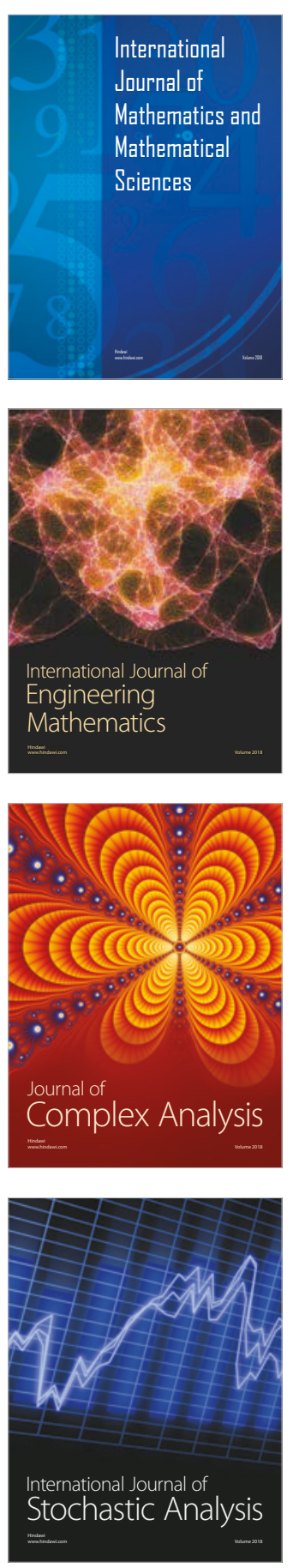
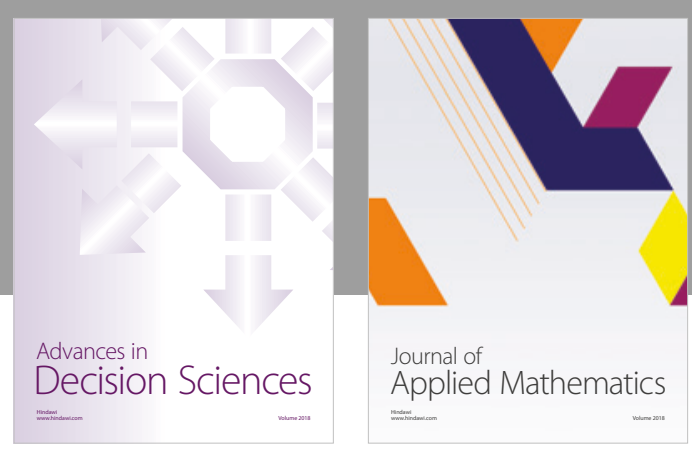

Journal of

Applied Mathematics
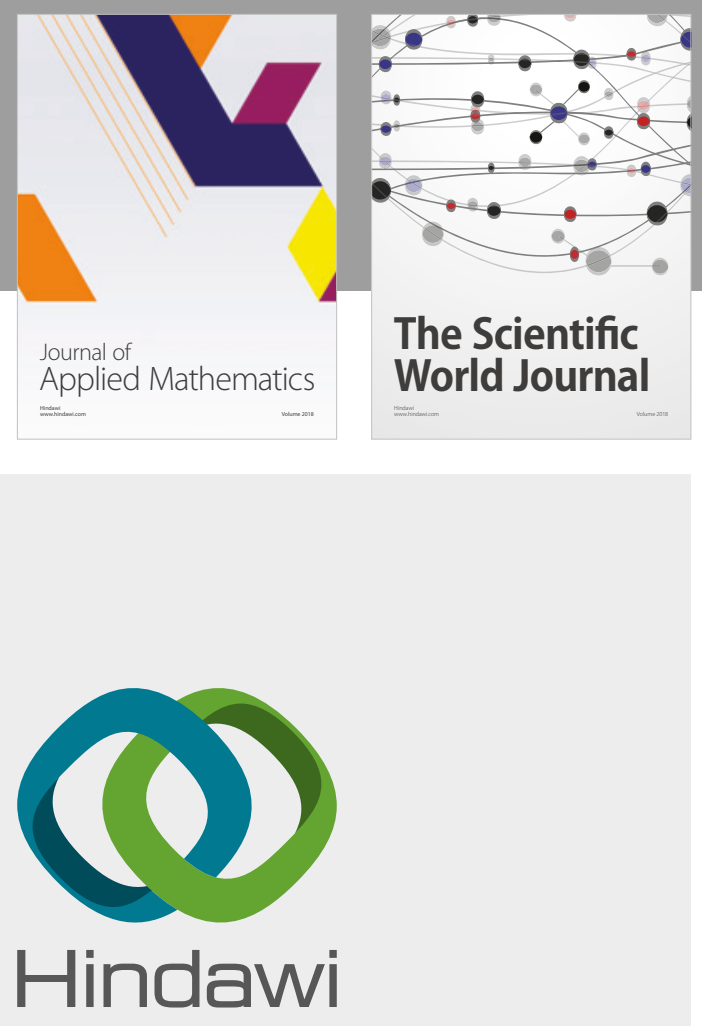

Submit your manuscripts at

www.hindawi.com

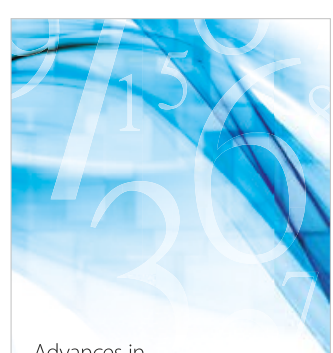

Advances in
Numerical Analysis
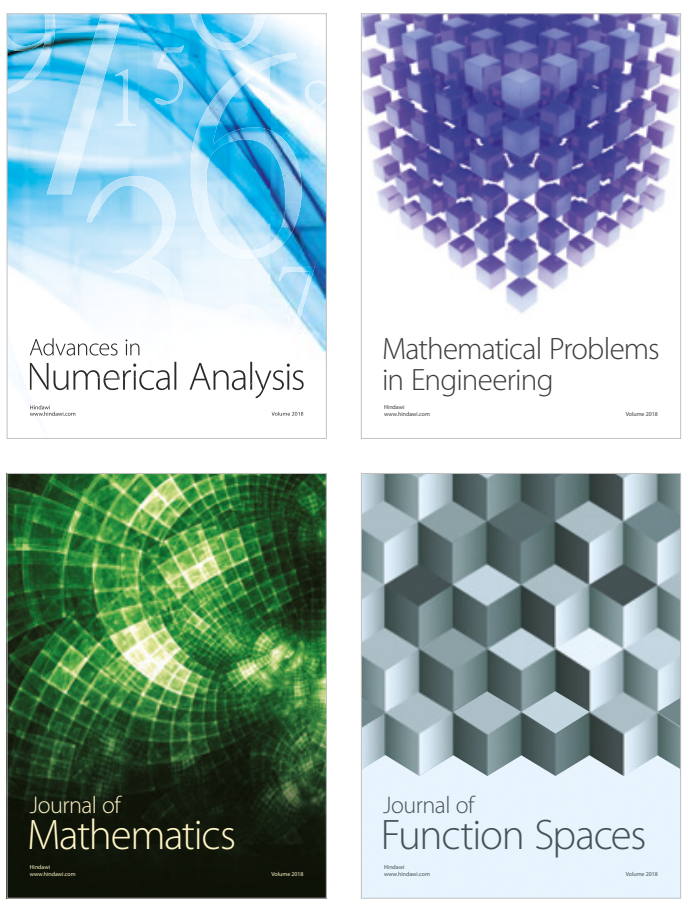

Mathematical Problems in Engineering

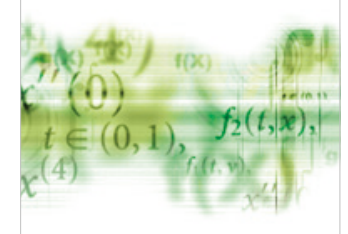

International Journal of

Differential Equations

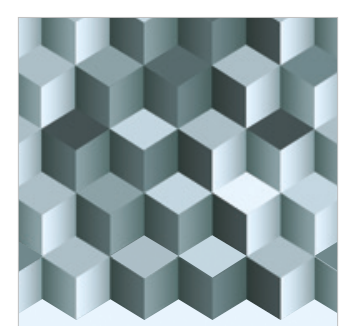

Journal of

Function Spaces
The Scientific

World Journal

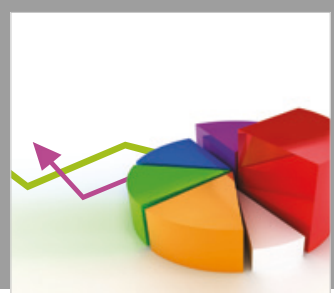

Journal of

Probability and Statistics
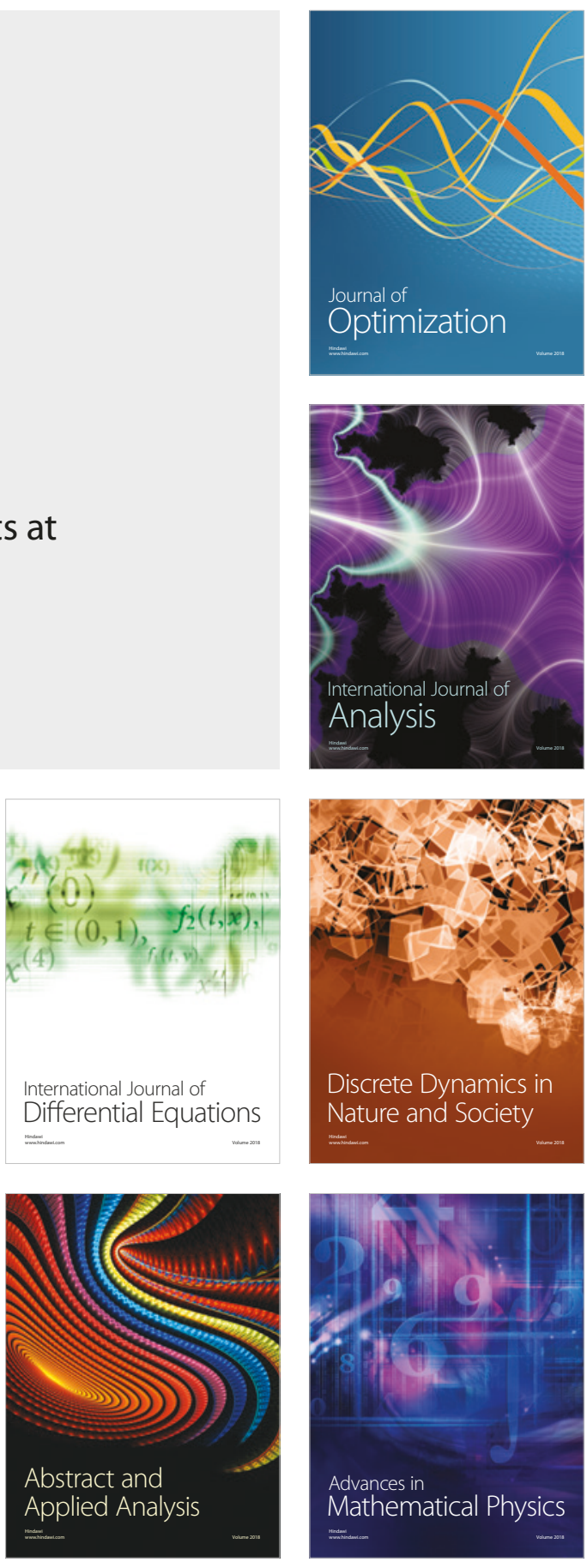